\title{
Lightning Characteristics Relative to Radar, Altitude and Temperature for a Multicell, MCS and Supercell over Northern Alabama
}

\author{
Retha M. Mecikalski \\ Lawrence D. Carey \\ Atmospheric Science Department \\ University of Alabama in Huntsville \\ 320 Sparkman Drive \\ Huntsville, Alabama 35805-1912
}

For publication in:

Atmospheric Research

09 January 2017
Corresponding Author: Retha Matthee Mecikalski
Atmospheric Science Department
University of Alabama in Huntsville National Space Science and Technology Center
320 Sparkman Drive
Huntsville, AL 35805-1912
E-mail: retha.mecikalski@nsstc.uah.edu
Phone: (256) 8244035




\begin{abstract}
Cloud electrification leads to the production of nitrogen oxides $\left(\mathrm{NO}_{\mathrm{x}}\right)$, which has an effect on ozone concentrations. Currently large uncertainties exist regarding the contribution of lightning to the global and local $\mathrm{NO}_{\mathrm{x}}$ budget, even on a per flash basis. Most lightning $\mathrm{NO}_{\mathrm{x}}\left(\mathrm{LNO}_{\mathrm{x}}\right)$ models distribute the $\mathrm{LNO}_{\mathrm{x}}$ at reflectivities $(\mathrm{Z}) \geq 20 \mathrm{dBZ}$ in the horizontal, while vertically, a Gaussian distribution function with a peak at $-15^{\circ} \mathrm{C}$ is used for cloud-to-ground (CG) flashes and a bimodal distribution function with peaks at $-15^{\circ} \mathrm{C}$ and $-45^{\circ} \mathrm{C}$ is used for inter- and intracloud (IC) flashes. This research aims to improve our basic understanding of lightning location relative to radar $\mathrm{Z}$ as a function of storm and flash type. Using data from the North Alabama Lightning Mapping Array (NALMA) and the Multi-Radar Multi-Sensor data suite, the results from analyzing a multicell storm, mesoscale convective system and supercell storm showed that $29.7 \%, 15.9 \%$ and $6.9 \%$ of all flashes initiated in regions where $\mathrm{Z}<20 \mathrm{dBZ}$, respectively. The bimodal lightning initiation distribution for IC flashes was also not observed for any of the three storms. In addition, it is shown that when incorporating the propagation of the flash, the percentage of NALMA lightning sources located in regions where $Z<20 \mathrm{dBZ}$ increases. Finally, when comparing flash types, the results show that Hybrid flashes have consistently larger sizes than IC and CG flashes, while IC and Hybrid flashes tend to have more sources located at $\mathrm{Z}<20 \mathrm{dBZ}$ than $\mathrm{CG}$ flashes.
\end{abstract}

\title{
Keywords:
}

Lightning, Reflectivity, Flash Type, $\mathrm{LNO}_{\mathrm{x}}$, Flash size 


\section{Introduction}

Cloud electrification is known to play an important role in the production of nitrogen oxides $\left(\mathrm{NO}_{\mathrm{x}}\right)$, which has an effect on ozone $\left(\mathrm{O}_{3}\right)$ concentrations. Stratospheric $\mathrm{O}_{3}$ is important as it shields the Earth from the Sun's harmful radiation, but tropospheric $\mathrm{O}_{3}$ absorbs infrared radiation, making it a greenhouse gas and a harmful pollutant. Davis et al. (1987); Murphy et al. (1993) and Hauglustaine et al. (2001) found that $\mathrm{NO}_{\mathrm{x}}$ concentrations in the upper $(10-15 \mathrm{~km})$ tropical troposphere are substantial, but that these concentrations are highly variable, while Singh et al. (1996); Zang et al. (2003) and Schumann and Huntrieser (2007) state that lightning is the dominant source of $\mathrm{NO}_{\mathrm{x}}$ production in the upper troposphere. Thus, improving the modeling of lightning-produced $\mathrm{NO}_{\mathrm{x}}\left(\mathrm{LNO}_{\mathrm{x}}\right)$ is very important, while numerical modeling of lightning flash type, rate, and length are significant due to their hypothesized role in the production of $\mathrm{NO}_{\mathrm{x}}$ (Price et al., 1997; Pickering et al., 1998; Wang et al., 1998; DeCaria et al., 2000, 2005; Dye et al., 2000; Ott et al., 2007; Barthe and Barth 2008). Various methods exist to calculate and disperse $\mathrm{LNO}_{\mathrm{x}}$ in a cloud; some of the differing methodologies are related to: (1) flash type, (2) flash size, (3) lightning location relative to altitude and reflectivity (Z), and (4) flash initiation. However none of these methodologies take storm type or flash propagation into account even though enough evidence exists to show that different storm types will have different charge structures and therefore different flash initiation and propagation characteristics (Marshall and Rust, 1991; Stolzenburg et al., 1994, 1998a,b,c; MacGorman and Rust, 1998; Schuur and Rutledge, 2000; Rakov and Uman, 2003). This research therefore aims to improve on the current lightning characteristics incorporated into $\mathrm{LNO}_{\mathrm{x}}$ modeling schemes by (1) distinguishing between three storm types (i.e., multicellular storm, mesoscale convective systems [MCSs] and a supercellular system), (2) distinguishing between three flash types (i.e., intra- and inter-cloud 
[IC], cloud-to-ground [CG] and Hybrids) and (3) including flash propagation instead of only using flash initiation or return stroke information. Although the analysis presented herein is based on only three storms (one of each type), future analysis will include multiple storms from each storm type.

\section{Background}

It is widely accepted that electrification is caused by the interaction of graupel and ice particles in the presence of supercooled liquid water through the non-inductive charging method (Takahashi, 1978; Saunders et al., 1991; Saunders, 1993; MacGorman and Rust, 1998; Rakov and Uman, 2003). Numerous studies have specifically examined the relationship between kinematic and microphysical properties of convective storms and their electrical behavior. Goodman et al. (1988); Carey and Rutledge (1996, 2000); Jameson et al. (1996); Bringi et al. (1997); Lang and Rutledge (2002); Wiens et al. (2005); Kuhlman et al. (2006); Bruning et al. (2007); Deierling and Petersen (2008); Deierling et al. (2008); and Mecikalski et al. (2015) reported that kinematic and microphysical radar properties trend well with lightning flash rates. The most important finding is that ice processes occurring in the mixed phase region $\left(0{ }^{\circ} \mathrm{C}\right.$ to -40 ${ }^{\circ} \mathrm{C}$ ) are critical for lightning to be observed. However, little research exists relating these radar properties to all components of a flash. This is partly because one needs various lightning instruments in order to record all the information from a lightning flash (such as a Lightning Mapping Array [LMA] network, a National Lightning Detection Network ${ }^{\mathrm{TM}}$ [NLDN], electric field mills, and many more, that range from the very low frequency [VLF] to the very high frequency $[\mathrm{VHF}]$ ) as each of these instruments record a different characteristic of a flash. For instance, NLDN records the current, multiplicity, latitude and longitude location of a return 
stroke at the ground, so there is no information on the flash propagation within the cloud. LMA, on the other hand, records information on electrical breakdown near the leader tip of a flash, but has no information about the return stroke.

Even with this lack of multiple lightning instruments observing the same storm, the combination of results from diverse research experiments has given us enough insight to understand that different storm types (such as multicellular storms, MCSs and supercells) will produce different electrical structures and therefore different lightning characteristics. Also, based on environmental characteristics needed for organization and longevity of storms (such as directional and speed shear in the lowest $6 \mathrm{~km}$ of the atmosphere, convective available potential energy [CAPE], moisture, etc.) and previous research that have shown that flash rate and updraft speed are correlated, storms with stronger updrafts (i.e., supercells) will have higher flash rates than storms with weaker updrafts (i.e., ordinary multicells). Furthermore, Carey et al. (2005); Dye and Willett (2007); Ely et al. (2008); Hodapp et al. (2008); Bruning and MacGorman (2013); and Calhoun et al. (2013) showed that flash sizes varied depending on the location within MCSs and supercells. Bruning and MacGorman (2013) specifically found an anti-correlation between flash rates and flash sizes for a supercell storm while Mecikalski et al. (2015) found this anti-correlation for a multicell storm.

There is also large variability in the charge structure within storms, although it is widely accepted that thunderstorms exhibit a dipole or tripole structure, with regions of opposite charge occurring in vertical layers (MacGorman and Rust, 1998; Rakov and Uman, 2003). Some studies have shown that this dipole/tripole structure may not be sufficient for all storm types (Marshall and Rust, 1991; Stolzenburg et al.; 1994, 1998a,b,c; Schuur and Rutledge, 2000). The charge regions (CRs) are related to the different charges that each hydrometeor carries (i.e., graupel, ice) 
after small-scale charge separation occurred in the cloud. The charged hydrometeors will then either be lofted by the updraft to higher altitudes, or fall due to gravitational forces to lower altitudes in the cloud, leading to storm-scale charge separation. The amount and vertical location of CRs in a cloud seem to be a function of both temperature and storm type (i.e., Marshall and Rust, 1991; Stolzenburg et al.; 1998a,b,c; MacGorman and Rust, 1998; Schuur and Rutledge, 2000; Rakov and Uman, 2003). Stolzenburg et al. (1998c) showed that the main negative CR is located at $-16{ }^{\circ} \mathrm{C}$ in convective regions of MCSs, at $-22{ }^{\circ} \mathrm{C}$ in supercell updrafts and at $-7{ }^{\circ} \mathrm{C}$ in New Mexican mountain storm updrafts (of the multicell type). In addition, Stolzenburg et al. (1998a) found at least four (six) CRs existed within (outside) updrafts of convective regions of MCSs, while Schuur et al. (1991) indicated that there were five CRs in the transition zone of MCSs, plus Stolzenburg et al. (1994) and Schuur and Rutledge (2000) showed that there were up to five CRs in the stratiform regions of MCSs. On the other hand, Stolzenburg et al. (1998b) found that within (outside) the updraft core of supercells, there were at least four (six to eight) CRs. In the "middle of small, isolated storms", as noted by Marshall and Rust (1991) it was found that anywhere between 2 and 7 different CRs existed, depending on the location of the storm (Alabama versus Oklahoma or New Mexico). Besides these differing CRs, research has shown that lightning in multicells tend to be concentrated in or near the updraft and reflectivity cores, while in supercell storms, lightning tends to be located outside the updraft and reflectivity cores, and within areas of reflectivity gradients (Ray et al., 1987; Steiger et al., 2007) while propagating either within the updraft core or into the anvil region (Weiss et al., 2012). However, both Kuhlman et al. (2009) and Weiss et al. (2012) observed lightning in supercells that initiated in the anvil region, while Kuhlman et al. (2009) noted that some flashes initiated in the anvil region and propagated towards the convective cores. For MCS storms, Carey et al. (2005) and 
Hodapp et al. (2008) noted that lightning tended to occur in a rearward and downward fashion from the back of the convective line into the stratiform region. Interestingly, Vuković and Curić (1998, 2005), using a 1-D cloud model, found that acoustic-electric effects caused by lightning may lead to enhanced droplet coalescence processes shortly after lightning occurs. This acousticelectric coalescence process leads to larger drops and therefore could lead to an increase in $\mathrm{Z}$ in regions where lightning occurs. Therefore, the relationship between lightning and its effect on the droplet spectra is also important. Due to the above, it is evident that when doing $\mathrm{LNO}_{\mathrm{x}}$ research, one has to distinguish between storm types, as each storm type has different lightning characteristics and thus should have different $\mathrm{LNO}_{\mathrm{x}}$ characteristics.

In addition to storm type not currently being taken into account in $\mathrm{LNO}_{\mathrm{x}}$ modeling, large uncertainty exists regarding $\mathrm{LNO}_{\mathrm{x}}$ production on a per flash basis (DeCaria et al. 2000). There is disagreement in the literature as to whether $\mathrm{CG}$ or IC flashes have different effects on $\mathrm{NO}_{\mathrm{x}}$ production (Price et al., 1997; Pickering et al., 1998; Dye et al., 2000; DeCaria et al., 2000, 2005; Ridley et al., 2005; Ott et al., 2007; Koshak et al., 2014; Carey et al., 2016). However, Hybrid flashes (as described by Bitzer et al., 2013) are effectively ignored or grouped into CG flashes in all the $\mathrm{LNO}_{\mathrm{x}}$ algorithms that do include flash typing. In short, Hybrid flashes are a combination of an IC flash, that usually travel large horizontal distances, before eventually coming to ground as a CG flash (and therefore producing a return stroke that is recorded by NLDN). According to Wang et al. (1998); Rakov and Uman (2003); and Barthe and Barth (2008) flash length may be important in $\mathrm{LNO}_{\mathrm{x}}$ modeling, with Barthe and Barth (2008) stating that large flashes (> $\left.30 \mathrm{~km}\right)$ contributed up to $80 \%$ to the total $\mathrm{NO}_{\mathrm{x}}$ produced in their study, although these large flashes only occurred $30 \%$ of the time. Defer et al. (2003); Ott et al (2007) and Carey et al. (2016) also incorporated flash sizes into their calculations of $\mathrm{LNO}_{\mathrm{x}}$ and although Carey et al. (2016) did not 
specifically separate Hybrid flashes from CG flashes, they showed that during times of higher $\mathrm{LNO}_{\mathrm{x}}$ production, flash sizes were larger and these flashes were Hybrid flashes.

Another weakness with current $\mathrm{LNO}_{\mathrm{x}}$ modeling schemes is where $\mathrm{LNO}_{\mathrm{x}}$ is distributed within a storm associated with lightning production. Barthe and Barth (2008) stated that the horizontal and vertical distribution of a flash is fundamental when modeling $\mathrm{LNO}_{\mathrm{x}}$. Many of the current $\mathrm{LNO}_{\mathrm{x}}$ parameterization schemes (i.e., Pickering et al., 1998; DeCaria et al., 2000, 2005; Barthe and Barth, 2008; Ott et al., 2010) distribute the $\mathrm{LNO}_{\mathrm{x}}$ uniformly in the horizontal where $\mathrm{Z} \geq 20$ dBZ. These methodologies also incorporate a vertical Gaussian distribution function for CG and a bimodal distribution function for IC flashes to compute where the $\mathrm{NO}_{\mathrm{x}}$ per flash will be distributed relative to a vertical temperature; the altitude of the maximum negative charge density is chosen as $-15^{\circ} \mathrm{C}$ for $\mathrm{CG}$ flashes and $-45^{\circ} \mathrm{C}$ (upper mode) and $-15^{\circ} \mathrm{C}$ (lower mode) for IC flashes (see also Figure 1 in DeCaria et al., 2000). The upper mode of the vertical distribution of IC flashes is modified as needed to account for higher or lower cloud tops (Ott et al., 2010). These assumptions are based on results presented by MacGorman and Rust (1998) who inferred their results after findings from Proctor (1991), which was based on a total of 773 flash initiation points only. However, lightning initiates where there is a strong electric field and propagates into regions where there is charge (i.e., as discussed in Bruning and MacGorman, 2013). Furthermore, Boccippio et al. (2000) and Hansen et al (2010) showed that peaks in the vertical distribution of LMA VHF sources (i.e., where flashes propagate) occur at different altitudes than was found for flash initiation points only, even for the same region when no distinction is made between storm types. As a result, one cannot ignore the remaining VHF sources and one cannot assume that the distributions are the same across different storm types. Moreover, Ivanov et al. (2014) showed that the highest volume content of NO production occurs at temperatures above a 
threshold between $\sim 3,000$ and 4,000 K, while stepped leaders have characteristic channel temperatures of $\sim 10,000 \mathrm{~K}$, as summarized in Rakov and Uman (2003), and because LMA detects the location of a leader tip, all sources of a lightning flash recorded by the LMA need to be taken into account when doing $\mathrm{LNO}_{\mathrm{x}}$ production estimates. Therefore, based on the above, this research is focused on improving our understanding of where lightning initiates and propagates relative to $\mathrm{Z}$ and altitude (or temperature), as a function of both storm and flash type.

\section{Data and Methods}

The North Alabama LMA (NALMA) consists of a total of 13 VHF sensors (11 sensors in northern Alabama and 2 sensors in north central Georgia) and is centered over the National Space Science and Technology Center (NSSTC, 34.724511 N, -86.644905 W) in Huntsville, AL (Koshak et al. 2004; Goodman et al. 2005). Using Monte Carlo simulations, Koshak et al. (2004) showed that within $100 \mathrm{~km}$ of the center of the network, typical horizontal and vertical spatial errors of NALMA detected sources were $\sim 50-500 \mathrm{~m}$ and on the order of $\sim 1 \mathrm{~km}$, respectively. In this research, only flashes that initiated within $\leq 100 \mathrm{~km}$ from NSSTC were used in the analysis. However, all NALMA sources that were related to these flashes were used in the analysis, so there may be some horizontal and vertical errors of $>500 \mathrm{~m}$.

The NLDN is a national lightning network across the continental U.S. (CONUS) that operates at the low frequency to VLF range and was used as a detector of CG and Hybrid flashes

in this study. The median location accuracy error associated with return strokes is on the order of 200-500 m (Cummins et al., 1998; and Biagi et al., 2007) and the detection efficiency across CONUS is $~ 95 \%$ (Cummins et al., 2006; Cummins and Murphy, 2009). In addition, a +15 kA 
threshold was applied for positive CG (+CG) flashes (Cummins et al., 1998, 2006; and Biagi et al., 2007).

The individual NALMA sources, together with data from the NLDN, were clustered into a lightning flash, based on spatial (maximum of $3 \mathrm{~km}$ between individual VHF sources in $\mathrm{x}, \mathrm{y}$ and altitude directions) and temporal (maximum of $0.15 \mathrm{~s}$ between individual VHF sources and $3 \mathrm{~s}$ for the entire flash) criteria, using xlma (Thomas et al., 2003). A minimum of 10 VHF sources were required for it to be classified as a flash in an attempt to remove erroneous radiation sources, such as noise (Wiens et al., 2005; Murphy, 2006; Schultz et al., 2009). For the flash initiation results, the first VHF source of each flash was used as the flash initiation point. The flash size of each flash, as well as each IC, CG and Hybrid flash was calculated as the square root of the convex hull (or polygon) area surrounding the sources in the horizontal, as in Bruning and MacGorman (2013) and Mecikalski et al. (2015).

As part of the flash clustering algorithm, each flash is classified per flash type (using xlma, Thomas et al., 2003). There are 11 flash types; for the overall flash results (i.e., when flash type is not specifically mentioned), all flash types were used and no distinction was made between the flashes. For the IC, CG and Hybrid specific comparisons, only flashes that were unambiguously classified (as in Table 1) were used in the analysis. The reason for only using unambiguously classified flashes is because even though many $\mathrm{LNO}_{\mathrm{x}}$ modeling studies distinguish between IC and CG flashes (by using NLDN as a flash type distinguisher) no study exists where Hybrid flashes were separately classified or where flash size was calculated as a function of flash type. If the flash size is indeed important in calculations of $\mathrm{LNO}_{\mathrm{x}}$, then it is important to analyze the sizes between these three flash types. Therefore, in order to not bias the results, all ambiguously 
classified flashes (i.e., "unclassified IC" or "unclassified flash") were removed from the flash dataset used to compare the IC, CG and Hybrid flash sizes.

The Multi-Radar Multi-Sensor (MRMS) data suite has made it possible to do radar-related analysis over CONUS with great ease. This system creates mosaic datasets of multiple radarbased products by using over $140 \mathrm{WSR}-88 \mathrm{D}$ radars. These radars have a $10.7 \mathrm{~cm}$ wavelength (Sband), with a range of $460 \mathrm{~km}(300 \mathrm{~km})$ for coastal (inland) radars when $\mathrm{Z}$ is measured (Zhang et al., 2011). From these radars, quality controlled 3D radar $\mathrm{Z}$ mosaic products are created in realtime over CONUS, spanning -130 to $-60^{\circ}$ (West) and 20 to $55^{\circ}$ (North), that is projected on a cylindrical equidistant map with a resolution of $0.01^{\circ}(\sim 0.638-1.045 \mathrm{~km}$ in the longitudinal and $\sim 1.112 \mathrm{~km}$ in the latitudinal direction, Lakshmanan et al., 2006, 2007, 2010; Zhang et al., 2004, 2005, 2011). The temporal resolution varies from 5 minutes prior to August 2013, where after it increases to 2 minutes.

The vertical profiles of lightning initiation and propagation information are imperative, as flashes initiate and propagate relative to where the CRs are located and these CRs are related to altitude and temperature profiles. As such, radiosonde data from the University of Wyoming's upper-air soundings website (http://weather.uwyo.edu/upperair/sounding.html) were used for the time and location closest to the storm in question, which included Birmingham (BMX), Nashville (BNA), the Redstone Arsenal and the University of Alabama in Huntsville (UAH).

There were three storm types that were considered: (1) a multicell storm that occurred on 20120521 during the Deep Convective Clouds and Chemistry (DC3) Field Campaign (also refer to Mecikalski et al., 2015; and Carey et al., 2016, for an in-depth analysis of this storm), (2) an MCS that occurred on 20140404, and (3) a supercell system that occurred on 20140428 over Northern Alabama. Figure 1 shows a summary depiction of the storms. Table 2, which is a 
summary of the convective parameters for each storm, shows that the 0-6 km shear increased from $2.0 \times 10^{-4} \mathrm{~s}^{-1}$ for the multicell, to $3.2 \times 10^{-4} \mathrm{~s}^{-1}$ for the MCS and $3.9 \times 10^{-4} \mathrm{~s}^{-1}$ for the supercell case. In addition, although the CAPE was higher for multicell $\left(785 \mathrm{~J} \mathrm{~kg}^{-1}\right)$ than for the MCS $\left(367 \mathrm{~J} \mathrm{~kg}^{-1}\right)$, it was highest for the supercell case at $1,276 \mathrm{~J} \mathrm{~kg}^{-1}$. These values of shear and CAPE roughly fit the conceptual model of multicells, MCSs and supercells (larger shear and CAPE values lead to more organization of storms), and therefore, based on previous research mentioned above, these three storms should exhibit different lightning characteristics.

Once the storms were chosen, the MRMS radar data obtained and the flashes clustered and classified as per the methods above, 2D histogram plots and vertical profiles of where the lightning flashes initiated and propagated were created for each storm. The 2D histogram data involved obtaining the $\mathrm{x}, \mathrm{y}$ and altitude location of each NALMA source point and then finding the $\mathrm{Z}$ value for that location. The data were binned into $5 \mathrm{~dB}$ intervals (for the horizontal axis) for $0.01<\mathrm{Z}<70 \mathrm{dBZ}$ and into $1 \mathrm{~km}$ intervals in the vertical from $0.01 \mathrm{~km}$ to the maximum height of the LMA sources associated with a flash (which varied). This $5 \mathrm{~dB}$ interval was chosen based on results from Gourley et al. (2003) where it was found that calibration differences among 10 WSR-88D radars could be as high as $7 \mathrm{~dB}$, while the mean difference varied between $\sim 0.5$ and $\sim 2.5 \mathrm{~dB}$. In order to minimize this calibration difference, MRMS incorporates an exponential weighting function, giving more weight to the closest radar and less weight to the radars further away from the storm (Zhang et al., 2005). This $5 \mathrm{~dB}$ bin size would then serve the purpose of (1) smoothing the data, and (2) being mostly larger than the calibration differences, thereby also accounting for possible inter-radar $\mathrm{Z}$ variations. A histogram was then created from either just the NALMA flash initiation point or for all VHF sources related to each flash (i.e., where the flash propagated), on a per-storm basis. The altitude of where the highest frequency of 
VHF sources occurred was then obtained and related to a range of temperatures for that altitude bin. These steps are repeated for all flashes, including those obtained for each flash type (i.e., IC, $\mathrm{CG}$ and Hybrid flashes).

\section{Possible Errors}

As stated, both NALMA and NLDN have location and detection efficiency errors; the largest location errors for NALMA occur in the vertical and could be on the order of $1 \mathrm{~km}$ at distances of $100 \mathrm{~km}$ or more (as modeled by Koshak et al., 2004). However, because a minimum of six sensors are used to obtain the $\mathrm{x}, \mathrm{y}$, and altitude locations of a source, these large location errors should be minimized. Histogram bin sizes were set to $1 \mathrm{~km}$ to further minimize the effect of the location errors. Finally, due to the larger location errors in the vertical, it was decided to not calculate the flash size relative to the "convex hull volume", but to only focus on the "convex hull area”. Also, Bruning and Thomas (2015) showed that the vertical distribution of the total convex hull channel length is approximately proportional to the vertical distribution of all VHF sources related to a flash. Therefore using the vertical distribution of these sources to weight $\mathrm{NO}_{\mathrm{x}}$ production, as done by Hansen et al. (2010), is appropriate (Bruning and Thomas, 2015).

Another point of error is related to the fact that all LMAs (and not just NALMA) do not detect positive breakdown in the negative $\mathrm{CR}$ as well as they detect negative breakdown in the positive $\mathrm{CR}$, because positive leader breakdown radiates less power than negative leader breakdown. Thomas et al. (2003) found that the source powers recorded by the New Mexico LMA ranged from $1 \mathrm{~W}$ up to $10-30 \mathrm{~kW}$ at $60-66 \mathrm{MHz}$, and that ICs radiated more power than CG flashes. As such, the first recorded LMA VHF source may not be the actual initiation point. However, because so many flashes were used in this analysis, and the focus is on the peak of the 
histogram, we are confident that even if a few flash initiation points were not truly the initiation point, our results are still valid. These sensitivities are another reason for $\mathrm{NO}_{\mathrm{x}}$ schemes to start applying the region where flashes propagate and using the "convex hull area" to calculate flash sizes - this way these location and detection efficiency errors are minimized and one obtains a more complete view of the flash.

NLDN is only used in the xlma algorithm to separate IC, CG and Hybrid flashes from each other. It is possible that because NLDN did not record a return stroke, or incorrectly recorded an IC return stroke as a CG return stroke (and vice versa), that some of the flash types may be ambiguous. However, xlma also takes leader velocity (i.e., direction and speed), whether single or bi-level breakdown was observed, and the location where $75 \%$ of the sources occurred into account when classifying flashes (Thomas et al., 2003). These ambiguously classified flashes are therefore due to (1) initial velocity errors or (2) location and/or detection efficiency errors of both NLDN and LMA data.

In addition, because VHF source grouping into flashes is based on time and location constraints, it is possible, especially for storms that produce very high flash rates, that some flashes were either grouped into a single flash, or a single flash was separated into more than one flash. Because the multicell and MCS flash rates were $\sim 5 \min ^{-1}$ and $\sim 65 \min ^{-1}$, respectively, we were not concerned that the VHF sources were incorrectly grouped into flashes. For the supercell, which had flash rates of up to $585 \mathrm{~min}^{-1}$, there is a chance that some of the VHF sources were not correctly grouped into flashes. However, the flash rates were obtained over a $10,000 \mathrm{~km}^{2}$ area, while the flash algorithm had a maximum distance of up to $3 \mathrm{~km}$ in the $\mathrm{x}, \mathrm{y}$, and altitude directions as well as a maximum time of 0.15 seconds between VHF sources in order for a source to form part of the flash. Therefore, in spite of the large flash rates of the 
supercell system, with the combination of the horizontal, vertical distance and time constraints, we are fairly confident that the VHF sources were correctly grouped into flashes.

Furthermore, not all of the VHF source points had co-located $\mathrm{Z}$ values. This could be due to some hydrometeor $\mathrm{Z}$ values being erroneously removed by the "clutter-removal" algorithm during MRMS processing. It is also important to note that there could be gaps in the radar data; at scan strategies higher than $\sim 4.3^{\circ}$, the vertical spacing of the elevation angles decreases relative to the beamwidth, while at scan strategies below $0.5^{\circ}$, there is a lack of sampling due to the earth's curvature. Both of these could lead to ring-shaped discontinuities in the radar data (Zhang et al., 2005). As such, whenever a VHF source point had no Z value co-located with it, the adjacent cell to the north, east, south and west was tested. If an adjacent point did have a Z, then this $\mathrm{Z}$ was used for the source point. If there were still no $\mathrm{Z}$ values available, then the source point was not included in the Z-source location calculations and therefore there were VHF sources (including those from the initiation calculations) that had no corresponding $\mathrm{Z}$ values. In some instances, this procedure would also serve as a quality control step of the NALMA data; if $\mathrm{Z}$ is well-sampled and quality controlled, then absent $\mathrm{Z}$ may imply that the VHF source was mislocated or was associated with noise.

Finally, as stated in the Introduction section, the analysis presented herein is based on only three storms, which undoubtedly may introduce uncertainties in the results, especially for the multicell case that produced only 104 flashes (21,866 VHF sources). However, the results for the MCS and the supercell case should be more robust, as these storms produced a total of 2,342 flashes (409,116 VHF sources) and 72,068 flashes (5,513,350 VHF sources), respectively, while in the domain. 


\section{Results}

As stated, three storms have been analyzed thus far; the first is a multicell storm that occurred on 20120521 during DC3 (Fig. 1a and b), the second is an MCS that occurred on 20140404 (Fig. 1c and d) and the third is an embedded supercell system that occurred on 20140428 (Fig. 1e and f). Note that for the supercell storm system, no distinction was made between the individual supercells, as this is very difficult because the flashes propagated into adjacent cells and there was no objective way to separate these flashes easily (see Fig. 1f). Figure 2 (a, c, e) shows the results when doing the 2D histogram of all flash initiation altitudes compared to $\mathrm{Z}$ for each storm type, while Figure 2 (b, d, f) shows the results for flash propagation, when no distinction is made between flash types for the multicell (Fig. 2a, b), MCS (Fig. 2c, d) and the supercell (Fig. 2e, f) storms. Note that for Figure 2 only NALMA initiation and propagation points with co-located $\mathrm{Z}$ values were included in the analysis; the percentages of points with $\mathrm{Z}$ values compared to all initiation points are shown in the top left of each plot. As shown, the distribution of flash initiation points varies both in terms of $\mathrm{Z}$ and altitude (and temperature) between the three storm types. In fact, for the multicell storm, $29.7 \%$ (Fig. 2a) and $47.1 \%$ (Fig. 2b) of the flashes initiated and propagated in $Z<20 \mathrm{dBZ}$, respectively. For the MCS these percentages are reduced to $15.9 \%$ (Fig. 2c) and $31.0 \%$ (Fig. 2d), respectively, while for the supercell, these percentages are further reduced to $6.9 \%$ (Fig. 2e) and $11.7 \%$ (Fig. 2f), respectively. This shows that more flashes propagate into lower reflectivity regions, irrespective of storm type, which could have significant impacts on where $\mathrm{NO}_{\mathrm{x}}$ is distributed in a storm. In addition, the altitude (temperature) at which the flashes initiate and propagate also varies, depending on storm type (refer to Table 3). More specifically, the temperature at which the maximum number of flashes initiated for the multicell, MCS and supercell were -13.5 to -20.5 
${ }^{\circ} \mathrm{C},-2.9$ to $-8.7{ }^{\circ} \mathrm{C}$, and -42.5 to $-50.6{ }^{\circ} \mathrm{C}$, respectively, indicating that the temperature difference could be as small as $\sim 10{ }^{\circ} \mathrm{C}$, but also as large as $\sim 40{ }^{\circ} \mathrm{C}$, depending on storm type. Furthermore, the temperature of the peak of the vertical VHF flash propagation also varies per storm type; it occurred at -28.3 to $-36.2{ }^{\circ} \mathrm{C}$ for the multicell, while for the MCS and supercell, the temperature changed to -22.5 to $-31.1{ }^{\circ} \mathrm{C}$ and -42.5 to $-50.6{ }^{\circ} \mathrm{C}$, respectively. Therefore, there are clear differences between where flashes initiate and propagate relative to storm type. This is similar to Hansen et al. (2010) who showed that the peak of the vertical VHF source distribution occurs at higher altitudes, as compared to the VHF flash initiation sources only, even when no distinction is made between storm types. However, Hansen et al. (2010) did note that considerable storm-tostorm and intra-storm variability occurred for four case studies that were analyzed. Our results show that for both the multicell and the MCS, the distribution of the VHF flash propagation relative to the distribution of VHF flash initiation sources are shifted to higher altitudes (colder temperatures). More specifically, there is a $+2 \mathrm{~km}$ and $\mathrm{a}+3 \mathrm{~km}$ increase in the peak altitude between where flashes initiated and propagated for the multicell and MCS cases, respectively. For the supercell case, there is no difference between the peak altitudes in flash propagation versus initiation. This could be related to findings by Pruppacher and Klett (1997) and Kumjian et al. (2012). Both showed that larger precipitation drops can take up to 4 minutes longer to freeze completely as compared to smaller precipitation drops at the same temperature, while Kumjian et al. (2012) found that stronger updrafts will lead to raindrops freezing at higher altitudes (colder temperatures) as compared to weaker updrafts. These findings could then lead to the altitude where non-inductive charging dominates also being located at higher altitudes (colder temperatures), while the charged particles themselves will be lofted to higher altitudes due to the stronger updrafts. This process could then lead to the elevated dipole as described by 
MacGorman et al. (1989); Lang et al. (2000); and Lang and Rutledge (2002). In fact, Lang et al. (2000) found an anti-correlation between storm intensity and CG flash rates, which they stated supports the elevated dipole theory. Although more detail about flash types is given later in this paper, $14.42 \%$ and $14.01 \%$ of all the flashes produced by the multicell and MCS cases (respectively) were unambiguously classified as CG flashes, while for the supercell case this is reduced to only $2.56 \%$. These findings are in accordance with Lang et al. (2000), indicating that for the supercell case, the main negative charge region may have been lofted to higher altitudes as compared to the multicell and MCS cases. Therefore, from our results, it seems that as the inferred updraft strength and CAPE increases (i.e., MCS is weakest, as we take the stratiform region into account as well [thereby reducing the overall inferred updraft strength], and the supercell is strongest), the altitude of the peak of the flash initiation and propagation increases, while the distance between the peak flash initiation and peak flash propagation decreases.

Figure 3 is essentially a conversion of Figure 2 from $2 D$ to $1 D$ as a function of $Z$ (Fig. 3a, c) and altitude (Fig. 3b, d) for flash initiation (Fig. 3a, b) and flash propagation (Fig. 3c, d) for the multicell (in red), MCS (in green) and supercell (in blue). From Figure 3 it is clear that the distribution of both flash initiation and flash propagation varies per storm type relative to both $\mathrm{Z}$ and altitude (temperature) and therefore one cannot assume that flash initiation and propagation is the same for different storm types. More specifically, and in relation to the discussion for Figure $2,10.9 \%, 5.4 \%$ and $11.0 \%$ of all flashes initiated, while $5.6 \%, 2.0 \%$, and $33.1 \%$ of all flashes propagated in regions where $\mathrm{Z} \geq 40 \mathrm{dBZ}$ for the multicell, MCS and supercell cases, respectively (see Table 4). Also, the peak of the Z-distribution varied per storm type; most of the lightning initiated between $25-30 \mathrm{dBZ}$ for both the multicell and the MCS, while for the supercell, this peak occurred between 40-45 dBZ (Fig. 3a). On the other hand, when flash 
propagation is taken into account (Fig. 3c), these Z-peaks change to $15-20 \mathrm{dBZ}$ for the multicell case, to 20-25 dBZ for both the MCS and supercell cases, with a secondary peak at $\sim 40-45 \mathrm{dBZ}$, for the supercell cases.

Figures 4-6 show the results for IC (Fig. 4), CG (Fig. 5) and Hybrid (Fig. 6) flashes specifically and are similar in description as for Figure 3. The first significant observation from Figure $4 \mathrm{~b}$ is that the bimodal distribution of IC flash initiation points as applied by many $\mathrm{LNO}_{\mathrm{x}}$ studies (see references above) is not observed and instead a single peak is observed for IC flashes irrespective of storm type. The distribution of $\mathrm{Z}$ relative to storm type for IC flashes also vary, with more flashes initiating (Fig. 4a) and propagating (Fig. 4c) at lower reflectivities for the multicell and MCS as compared to the supercell storm (also refer to Table 4). On the other hand, more IC flashes initiate and propagate in higher $\mathrm{Z}(\geq 40 \mathrm{dBZ}$ ) for the supercell as compared to the multicell and MCS. Furthermore, the altitudes of where IC flashes initiated (Fig. 4b) and propagated (Fig. 4d) also varies for the three storm types, especially for the flash initiation points, with IC flashes from supercells initiating at altitudes $\sim 4 \mathrm{~km}$ higher $\left(\sim 27^{\circ} \mathrm{C}\right.$ colder $)$ than observed for the multicell and MCS systems (refer also to Table 3 for IC, CG and Hybrid flash initiation and propagation temperatures and altitudes). The elevated dipole theory, as explained earlier, could also explain why IC flashes in the supercell initiate and propagate at higher altitudes than the multicell and MCS. These differences in initiation and propagation altitudes for storm types are also applicable to the Hybrid flashes (Fig. 6). The difference in the CG flashes (Fig. 5) is not as apparent as for the IC (Fig. 4) and Hybrid (Fig. 6) flashes.

Fewer CG flashes (Fig. 5) initiated and propagated into $\mathrm{Z}<20 \mathrm{dBZ}$ as compared to IC flashes, while more CG flashes initiated and propagated into $Z \geq 40 \mathrm{dBZ}$ (refer to Table 4) irrespective of storm type. The altitudes of initiation and propagation of CG flashes were not 
much different between the three storm types and were centered around $\sim 2.0-5.0 \mathrm{~km}(\sim+5$ to -5 ${ }^{\circ} \mathrm{C}$ ), although this is at least $10^{\circ} \mathrm{C}$ warmer than what is currently used for the CG flash initiation distributions in $\mathrm{LNO}_{\mathrm{x}}$ models. On the other hand, fewer Hybrid flashes initiated at $\mathrm{Z}<20 \mathrm{dBZ}$ as compared to IC flashes (Table 4), while the results for the Hybrid flash propagation appear to fall between those found for IC and CG flash propagations. Hybrid flashes also have fewer flashes initiating and propagating at $\mathrm{Z} \geq 40 \mathrm{dBZ}$ as compared to $\mathrm{CG}$ flashes, but with comparable values as found for IC flashes. This is not unexpected, as IC and Hybrid flashes tend to initiate and propagate at higher altitudes in storms, where precipitation particle sizes are usually smaller and frozen as compared to $\mathrm{CG}$ flashes that initiate and propagate at lower altitudes where precipitation particle sizes are larger and consist of a mixture of frozen and liquid particles. In addition, there were differences of up to $4 \mathrm{~km}\left(\sim 20^{\circ} \mathrm{C}\right)$ and up to $2 \mathrm{~km}\left(\sim 12{ }^{\circ} \mathrm{C}\right)$ in both the Hybrid initiation and propagation altitudes, respectively, between the multicell and MCS and the multicell and supercell storms.

Finally, Table 5 shows the percentage of occurrence of each flash type relative to all flashes as well as how the mean size of each flash type compares to the mean size of all the flashes. For all cases, Hybrid flashes are consistently the largest; while IC's >CG's for the multicell and MCS cases but <CG for the supercell case. In fact, Hybrid flashes are at least 1.44 the size of IC flashes and >1.96 the size of CG flashes for the multicell and MCS. For the supercell case, Hybrid flashes are 1.12 and 1.71 larger than the size of CG and IC flashes, respectively. This could be related to the stronger updrafts in this type of storm, which will lead to higher flash rates and thus smaller flash sizes across the board (Bruning and MacGorman, 2013). For the multicell storm, even though Hybrid flashes only made up $6.73 \%$, while CG flashes made up $14.42 \%$ of all the flashes (here "all" flashes includes the flashes that are ambiguously classified), 
Hybrid flashes comprised $10.5 \%$ while CG flashes comprised only $9.95 \%$ of the total size relative to all flashes (the total size here means that all the sizes from all the flashes were summed for the entire storm). For the MCS case however, Hybrid flashes only occurred $16.23 \%$ of the time, but their total flash size contribution to the storm is $26.20 \%$, this is more than was obtained for the IC and CG flashes. For the supercell case, Hybrid flashes actually occurred more often than CG flashes ( $8.08 \%$ compared to $2.56 \%$, respectively), and also had a larger total size contribution as compared to CG flashes (13.44 \% versus $3.82 \%)$; this, again, could be related to the elevated dipole theory (MacGorman et al., 1989; Lang et al., 2000; Lang and Rutledge, 2002). The above shows that it is imperative to separately classify Hybrid flashes from CG flashes in $\mathrm{LNO}_{\mathrm{x}}$ models that do flash typing and/or include flash size in their calculations (such as Pickering et al., 1998; DeCaria et al., 2000, 2005; Defer et al., 2003; Ott et al., 2007, 2010; and Barthe and Barth, 2008). If Hybrid flashes are not separately classified, and IC versus CG classification is dependent on NLDN only, then Hybrid flashes will be grouped into the CG flash category. Thus, the amount and location of $\mathrm{LNO}_{\mathrm{x}}$ production per $C G$ flash type will be skewed due to: (1) Hybrid flashes being consistently larger in size than CG flashes (as well as IC flashes) and therefore will lead to more $\mathrm{NO}_{\mathrm{x}}$ being produced than CG flashes (as well as IC flashes) and (2) Hybrid flashes have more VHF sources that initiate and propagate in regions where $\mathrm{Z}<20 \mathrm{dBZ}$ as compared to CG flashes, while the vertical distribution of VHF initiation and propagation sources are very different from CG flashes, but similar to IC flashes.

Lastly, as the CAPE and the inferred updraft strength increased from the MCS to the multicell and finally to the supercell, the overall mean flash size per storm type decreased. This decrease in flash size as the inferred updraft strength and CAPE increases also leads to more confidence that the xlma flash grouping algorithm performed well for the supercell case, 
otherwise the flash sizes for this case would've been much larger and the total number of flashes would have been much lower.

\section{Discussion and Conclusions}

Three storms were analyzed to compare their lightning characteristics to radar $\mathrm{Z}$ and altitude. These storms included a multicell storm (20120521), an MCS (20140404) and an embedded supercell system (20140428) over northern Alabama. A total of 104 (multicell), 2,342 (MCS) and 72,068 (supercell) flashes were used in the analysis. It was shown that even if one only compares flash initiation points, the altitude and $\mathrm{Z}$ at which flashes initiate vary per storm type and could be related to updraft strength. The peak of the VHF flash initiation source points for the multicell occurred at higher altitudes (colder temperatures) than for the MCS, but at much lower altitudes (much warmer temperatures) than for the supercell, with a difference of up to $\sim 6$ $\mathrm{km}\left(40^{\circ} \mathrm{C}\right)$ between the three storm types. In addition, it is shown that $\mathrm{LNO}_{\mathrm{x}}$ cannot only be distributed where $Z \geq 20 \mathrm{dBZ}$, as flashes both initiate and propagate in regions where $Z<20$ $\mathrm{dBZ}$. It is also shown that more flashes initiate and propagate in $\mathrm{Z}<20 \mathrm{dBZ}$ for the multicell than for the MCS and supercell, while more flashes initiate and propagate in $\mathrm{Z} \geq 40 \mathrm{dBZ}$ for the supercell than for the multicell and MCS. Therefore, even if no distinction is made between flash types, and only flash initiation points are used in $\mathrm{LNO}_{\mathrm{x}}$ models, then differentiating between storm types with respect to the vertical distribution of initiation points and horizontal distribution of $\mathrm{Z}$, will lead to improved $\mathrm{LNO}_{\mathrm{x}}$ production rates.

On the other hand, we show there is a clear difference between where flashes initiate and propagate relative to both $\mathrm{Z}$ and altitude (temperature) for all three storm types. In particular, we show that the difference between the peak initiation and peak propagation altitude decreases as 
the inferred updraft strength and CAPE increases, in accordance with the elevated dipole theory. We also show that it is important to include the region where flashes propagate, as $\mathrm{LNO}_{\mathrm{x}}$ production is a function of temperature, and LMAs record leaders with temperatures $>10,000 \mathrm{~K}$. Therefore one cannot ignore these flash propagation regions if accurate $\mathrm{LNO}_{\mathrm{x}}$ production is required. In fact, for the multicell, $29.7 \%$ and $47.1 \%$ of all flashes initiated and propagated, respectively, in regions where $\mathrm{Z}<20 \mathrm{dBZ}$. Because multicellular convective storms occur most often out of the three storm types analyzed, it means that at minimum, $30 \%$ of the $\mathrm{LNO}_{\mathrm{x}}$ that is produced by certain models will be distributed in the incorrect location for flash initiation points (both horizontally and vertically) and this percentage is increased to almost half of the $\mathrm{LNO}_{\mathrm{x}}$ production when one considers flash propagation. It is also shown that more flashes propagate than initiate in regions of lower $\mathrm{Z}$.

When flash typing is included in the analysis, we show that the bimodal vertical distribution of IC flash initiation points, that have been used by many in current $\mathrm{LNO}_{\mathrm{x}}$ parameterization schemes, are not evident in the three storms analyzed here and that only a single peak is found, irrespective of storm type. In addition, the $-45^{\circ} \mathrm{C}$ upper mode in the bimodal distribution function is almost $30^{\circ} \mathrm{C}$ too cold for the multicell and MCS storms, but seems to be appropriate for the supercellular storm. Even when flash propagation is included, this upper mode is too cold by approximately $20^{\circ} \mathrm{C}$ for both the multicell and MCS storms. For CG flashes, it was shown that the peak of the distribution of flash initiation and propagation VHF source points are located at temperatures almost $20{ }^{\circ} \mathrm{C}$ warmer for the multicell case and up to $\sim 10{ }^{\circ} \mathrm{C}$ warmer for both the MCS and supercellular storm cases. In addition, both IC and CG flashes had initiation and propagation points in $\mathrm{Z}<20 \mathrm{dBZ}$, with the percentage of occurrence in $\mathrm{Z}<20 \mathrm{dBZ}$ decreasing with increasing storm intensity. In fact, if one only takes the multicell storm into account, $40.9 \%$ 
and $54.4 \%$ of IC flashes initiated and propagated, respectively, in regions where $Z<20 \mathrm{dBZ}$, while these percentages are reduced by $\sim 25$ to $30 \%$ for CG flashes. These findings clearly show that if $\mathrm{LNO}_{\mathrm{x}}$ is only distributed uniformly in regions where $\mathrm{Z}>20 \mathrm{dBZ}$, and following a bimodal and Gaussian vertical distribution function for IC and CG flashes, respectively, while assuming all storm types have the exact same lightning characteristics, one would incorrectly distribute the $\mathrm{LNO}_{\mathrm{x}}$ both horizontally and vertically in a cloud.

Finally, past research also only distinguishes between IC and CG flashes and either ignore Hybrid flashes or group these flashes with CG flashes. It is shown herein that Hybrid flashes need to have their own separate classification, as these flashes consistently have larger sizes than both IC and CG flashes, irrespective of storm type. Also, Hybrid flashes, like IC flashes, initiate and propagate in lower Z's than CG flashes. Because of this, Hybrid flashes cannot be ignored and also cannot be grouped into the CG category. If Hybrid flashes are ignored, the total $\mathrm{LNO}_{\mathrm{x}}$ production per storm may be reduced by at least $10 \%$ if only flash size is taken into consideration; if Hybrid flashes are grouped with CG flashes, the total $\mathrm{LNO}_{\mathrm{x}}$ production of CGs will be distributed in the incorrect location, both vertically and horizontally, and the total $\mathrm{LNO}_{\mathrm{x}}$ production from CGs will be increased if flash size is included in the parameterization scheme.

Because the results herein are based on only three storms, it is clear that a larger sample of additional storms are needed in order to verify the above-mentioned results relative to storm and flash type. As such, ongoing work includes analyzing numerous storms for each of these storm types and statistically verifying the differences between the storm and flash types. The results from this statistical analysis will be used to create a methodology that is more appropriate for use in $\mathrm{LNO}_{\mathrm{x}}$ parameterization schemes than is currently being used. 


\section{Acknowledgements}

We wish to recognize funding from the National Science Foundation`s Physical and Dynamical Meteorology (NDF PDM) Program (grant number AGS-1063573), which has supported the DC3 field experiment and associated research. We wish to thank the many people who made the collection of DC3 observations possible and NOAA/NSSL for providing the MRMS 3D Z mosaic data used herein. Finally, we wish to thank the anonymous reviewers for comments that have improved the quality of this research paper. 


\section{Glossary}

CG Cloud-to-ground flash

CR Charge (or charging) region

IC Inter- or intra-cloud flash

LMA Lightning mapping array

$\mathrm{LNO}_{\mathrm{x}} \quad$ Lightning-produced nitrogen oxides

MCS Mesoscale convective system

MRMS Multi-radar multi-sensor

NALMA North Alabama lightning mapping array

NLDN National Lightning Detection Network ${ }^{\text {TM }}$

$\mathrm{NO}_{\mathrm{x}} \quad$ Nitrogen oxides, $\mathrm{NO}_{\mathrm{x}}=\mathrm{NO}+\mathrm{NO}_{2}$

NSSTC National space science and technology center

VHF Very high frequency

VLF Very low frequency

$\mathrm{Z} \quad$ Horizontal reflectivity 


\section{References}

Barthe, C., M.C. Barth, 2008. Evaluation of a new lightning-produced $\mathrm{NO}_{\mathrm{x}}$ parameterization for cloud resolving models and its associated uncertainties, Atmos. Chem. Phys., 8, 46914710.

Barth, M. C., C. A. Cantrell, W. H. Brune, S. A. Rutledge, J. H. Crawford, H. Huntrieser, L. D. Carey, D. MacGorman, M. Weisman, K. E. Pickering, E. Bruning and co-authors, 2015. The Deep Convective Clouds and Chemistry (DC3) Field Campaign, Bull. Amer. Meteor. Soc., 96, 1281-1309, doi: http://dx.doi.org/10.1175/BAMS-D-13-00290.1.

Biagi, C.J., K.L. Cummins, K.E. Kehoe, P. Krider, 2007. National Lightning Detection Network (NLDN) performance in southern Arizona, Texas, and Oklahoma in 2003-2004, J. Geophys Ress. 112, D05208.

Bitzer, P.M., H.J. Christian, M. Stewart, J. Burchfield, S. Podgorny, D. Corredor, J. Hall, E. Kuznetsov, V. Franklin, 2013. Characterization and applications of VLF/LF source locations from lightning using the Huntsville Alabama Marx Meter Array, J. Geophys. Res. Atmos., 118, $3120-3138$.

Bringi, V.N., K. Knupp, A. Detwiler, L. Liu, I. J. Caylor, and R. A. Black, 1997. Evolution of a Florida thunderstorm during the Convection and Precipitation/Electrification Experiment: The case of 9 August 1991. Mon. Wea. Rev., 125, 2131-2160, doi:10.1175/15200493(1997)125,2131:EOAFTD.2.0.CO;2.

Boccippio, D.J., S. Heckman, S.J. Goodman, 2000. A diagnostic analysis of the Kennedy Space Center LDAR network 1. Data characteristics, J. Geophys. Res., 106, 4769-4786, doi:10.1029/2000JD900687. 
Bruning, E.C. and D.R. MacGorman, 2013. Theory and observations of controls on lightning flash size spectra, J. Atmos. Sci., 70, 4012-4029.

Bruning, E.C., W.D. Rust, T.J. Schuur, D.R. MacGorman, P.R., Krehbiel, and W. Rison, 2007. Electrical and polarimetric radar observations of a multicell storm in TELEX, Mon. Wea. Rev., 135, 2525-2544, doi:10.1175/MWR3421.1.

Bruning, E.C. and R.J. Thomas, 2015. Lightning channel length and flash energy determined from moments of the flash area distribution, J. Geophys. Res. Atmos., 120, 8925-8940, doi: 10.1002/2015JD023766.

Calhoun, K.M., D.R. MacGorman, C.L. Ziegler, M.I. Biggerstaff, 2013. Evolution of lightning activity and storm charge relative to dual-doppler analysis of a high-precipitation supercell storm, Mon. Wea. Rev., 141, 2199-2223.

Carey, L. D., W. Koshak, H. Peterson, and R. M. Mecikalski, 2016: The kinematic and microphysical control of lightning rate, extent and $\mathrm{NO}_{\mathrm{X}}$ production. J. Geophys. Res. Atmos., 121, 7975-7989, doi:10.1002/2015JD024703.

Carey, L. D. and S. A. Rutledge, 1996. A multiparameter radar case study of the microphysical and kinematic evolution of a lightning producing storm. J. Meteorol. Atmos. Phys., 59, 33-64.

Carey, L. D. and S. A. Rutledge, 2000. The relationship between precipitation and lightning in tropical island convection: A C-Band polarimetric radar study. Mon. Wea. Rev., 128, 2687-2710.

Carey, L.D., M.J. Murphy, T.L. McCormick and N.W.S. Demetriades, 2005. Lightning location relative to storm structure in a leading-line, trailing-stratiform mesoscale convective system. J. Geophys. Res., 110, D03105. 
Cummins, K.L., M.J. Murphy, E.A. Bardo, W.L. Hiscox, R.B. Pyle, A.E. Pifer, 1998. A combined TOA/MDF technology upgrade of the U.S. National Lightning Detection Network, J. Geophys. Res., 103, 9035-9044.

Cummins, K.L., J.A. Cramer, C.J. Biaji, E.P. Krider, J. Jerauld, M.A. Uman, V.A. Rakov, 2006. The U.S. National Lightning Detection Network: Post-upgrade status. Preprints, $2^{\text {nd }}$ Conference on Meterological Applications of Lightning Data, January 29-February 2, Atlanta, GA, American Meteorological Society, 9 pp.

Cummins, K.L., and M.J. Murphy, 2009. An Overview of Lightning Locating Systems: History, Techniques, and Uses, With an In-depth Look at the U.S. NLDN, IEEE Transactions on Electromagnetic Compatibility, Vol. 51, 499-518.

Davis, D.D., J.D. Bradshaw, M.O. Rodgers, S.T. Sandholm, S. KeSheng, 1987. Free tropospheric and boundary layer measurements of NO over the central and eastern North Pacific ocean, J. Geophys. Res., 92, $2049-2070$.

DeCaria, A.J., K.E. Pickering, G.L. Stenchikov, J.R. Scala, J.L. Stith, J.E. Dye, B.A. Ridley and P. Laroche, 2000. A cloud-scale model study of lightning-generated $\mathrm{NO}_{\mathrm{X}}$ in an individual thunderstorm during STERAO-A, J. Geophys. Res., 105, 11601-11616.

DeCaria, A.J., K.E. Pickering, G.L. Stenchikov, and L.E. Ott, 2005. Lightning-generated NOX and its impact on tropospheric ozone production: A three-dimensional modeling study of a Stratosphere-Troposphere Experiment: Radiation, Aerosols and Ozone (STERAO-A) thunderstorm, J. Geophys. Res. 110, D14303.

Defer, E., P. Laroche, J. E. Dye, and W. Skamarock, 2003. Use of total lightning lengths to estimate NOx production in a Colorado thunderstorm, $12^{\text {th }}$ International Conference on Atmospheric Electricity, June 9 -13, Versailles, France. 
Deierling W., W.A. Petersen , J. Lantham, S. Ellis., H.J. Christian Jr., 2008. The relationship between lightning activity and ice fluxes in thunderstorms, J. Geophys Res., 113, D15210, doi:10.1029/2007JD009700.

Deierling W., W.A. Petersen, 2008. Total lightning activity as an indicator of updraft characteristics, J. Geophys Res., 113, D16210, doi:10.1029/2007JD009598.

Dye, J.E., and co-authors, 1986. Early electrification and precipitation development in a small, isolated Montana cumulonimbus, J. Geophys. Res., 91, 1231-1247.

Dye, J.E., and co-authors, 2000. An overview of the Stratospheric-Tropospheric Experiment Radiation, Aerosols, and ozone (STERAO)-Deep Convective experiment with results for the July 10, 1996 storm, J. Geophys. Res., 105, 10023-10045.

Dye J.E., and J.C. Willett, 2007. Observed enhancement of reflectivity and the electric field in long-lived Florida anvils, Mon. Wea. Rev., 135, 3362-3380.

Ely, B.L., R.E. Orville, L.D. Carey and C.L. Hodapp, 2008. Evolution of total lightning structure in a leading-line, trailing stratiform mesoscale convective system over Houston, Texas, $J$. Geoph. Res., 113, D08114.

Goodman, S.J., D.E. Buechler, P.D. Wright, and W.D. Rust, 1988. Lightning and precipitation history of a microburst-producing storm, Geophys. Res. Lett., 15, 1185-1188, doi:10.1029/GL015i011p01185.

Goodman S.J, R. Blakeslee, H. Christian, W. Koshak, J. Bailey, J. Hall, E. McCaul, D. Buechler, C. Darden, J. Burks, T. Bradshaw, P. Gatlin, 2005. The North Alabama Lightning Mapping Array: Recent severe storm observations and future prospects, Atmos. Res., 76, $423-437$. 
Gourley, J.J., B. Kaney, R.A. Maddox, 2003. Evaluating the calibrations of radars: A software approach, Preprints, $31^{\text {st }}$ Int. Conf. on Radar Meteorology, Seattle, WA, Amer. Meteor. Soc., $459-462$.

Hansen, A.E., H.E. Fuelberg, K.E. Pickering, 2010. Vertical distributions of lightning sources and flashes over Kennedy Space Center, Florida, J. Geophys. Res., 115, D14203, doi:10.1029/2009JD013143.

Hauglustaine, D., L. Emmons, M. Newchurch, G. Brasseur, T. Takao, K. Matsubara, J. Johnson, B. Ridley, J. Stith, J. Dye, 2001. On the role of lightning $\mathrm{NO}_{\mathrm{x}}$ in the formation of tropospheric ozone plumes: A global model perspective, J. Atmos. Chem., 38, 277 - 294.

Hodapp, C.L., L.D. Carey and R.E. Orville, 2008. Evolution of radar reflectivity and total lightning characteristics of the 21 April 2006 mesoscale convective system over Texas, Atmos. Res., 89, 113-137.

Houze, R.A., 1993. Cloud Dynamics, Academic Press, pp. 573.

Ivanov, M.F., A.D. Kiverin, B.A. Klumov, V.E. Fortov, 2014. From combustion and detonation to nitrogen oxides, Physics, 57 (3), 234-249.

Jameson, A.R., M.J. Murphy, and E.P. Krider, 1996. Multiple-parameter radar observations of isolated Florida thunderstorms during the onset of electrification, J. Appl. Meteor., 35, $343-354$.

Koshak, W.J., A.P. Biazar, M.N. Khan, L. Wang, 2014. The NASA lightning nitrogen oxides model (LNOM): Application to air quality modeling, Atmos. Res. 135-136, 363 - 369.

Koshak, W.J., and co-authors, 2004. North Alabama Lightning Mapping Array (LMA): VHF source retrieval algorithm and error analyses, J. Atmos. Oceanic Technol., 21, 543-558. 
Koshak, W.J., R.J. Solakiewicz, H.S. Peterson (2015), A return stroke NOx production model, $J$. Atmos. Sci., 72, No. 2, 943-954.

Kuhlman, K.M., D.R. MacGorman, M.I. Biggerstaff, P.R. Krehbiel, 2009. Lightning initiation in the anvils of two supercell storms, Geophys. Res. Let., 36, L07802.

Kuhlman, K.M., C.L. Ziegler, E.R. Mansell, D.R. MacGorman, J.M. Straka, 2006. Numerically simulated electrification and lightning of the 29 June 2000 steps supercell storm. Mon. Wea. Rev., 134, 2734-2757.

Kumjian, M.R., S.M. Ganson, A.V. Ryzhkov, 2012. Freezing of raindrops in deep convective updrafts: A microphysical and polarimetric model, J. Atmos. Sci, 69, 3471-3490.

Lakshmanan, V., A. Fritz, T. Smith, K. Hondl, G.J. Stumpf, 2007. An automated technique to quality control radar reflectivity data, J. Appl. Meter. Climatol., 46, 288 - 305.

Lakshmanan, V., T. Smith, K. Hondl, G.J. Stumpf, A. Witt, 2006. A real-time, threedimensional, rapidly updating, heterogeneous radar merger technique for reflectivity, velocity, and derived products, Weather and Forecasting, 21, 802-823.

Lakshmanan, V., J. Zhang, K. Howard, 2010. A technique to censor biological echoes in weather radar images, J. Appl. Meter. Climatol., 49, 453 - 462.

Lamarque, J.-F., G.P. Brasseur, P.G. Hess, J.-F. Mueller, 1996. Three-dimensional study of the relative contributions of the different nitrogen sources in the troposphere, J. Geophys, Res., 95, 9971-9981.

Lang, T.J, S.A. Rutledge, 2002. Relationships between Convective Storm Kinematics, Precipitation, and Lightning, Mon. Wea. Rev., 130, 2492-2506. 
Lang, T.J., S.A. Rutledge, J.E. Dye, M. Venticinque, P. Laroche, E. Defer, 2000. Anomalously low negative cloud-to-ground lightning flash rates in intense convective storms observed during STERAO-A, Mon. Wea. Rev., 128, 160-173.

MacGorman, D.R., D.W. Burgess, V. Mazur, W.D. Rust, W.L. Taylor, B.C. Johnson, 1989. Lightning rates relative to tornadic storm evolution on 22 May 1981, J. Atmos. Sci., 46, 221-250.

MacGorman, D.R., and Rust, W.D., 1998. The Electrical Nature of Storms, Oxford University Press, New York, pp 422.

Markowski, P., and Y. Richardson, 2010. Mesoscale Meteorology in Midlatitudes, WileyBlackwell Publishers, 407 pp.

Marshall, T.C. and W.D. Rust, 1991. Electric field soundings through thunderstorms, J. Geophys, Res., 96 (D12), 22,297 - 22,306.

Mecikalski, R.M., A.L. Bain, L.D. Carey, 2015. Radar and lightning observations of deep moist convection across Northern Alabama during DC3: 21 May 2012, Mon. Wea. Rev., 143, $2774-2794$.

Murphy, M.J., 2006. When Flash Algorithms Go Bad. $19^{\text {th }}$ International Lightning Detection Conf., Tucson, AZ. Vaisala International Lightning Detection Conf.

Murphy, D.M., D.W. Fahey, M.H. Proffitt, S.C. Liu, K.R. Chan, C.S. Eubank, S.R. Kawa, K.K. Kelley, 1993. Reactive nitrogen and its correlation with ozone in the lower stratosphere and upper troposphere, J. Geophys. Res., 98, $8751-8773$.

Navarro-González, R., M. Villagrán-Muniz, H. Sobral, L.T. Molina, M.J. Molina, 2001. The physical mechanism of nitric oxide formation in simulated lightning, Geophys. Res. Let., 28 (20), $3867-3870$. 
Ott, L.E., K.E. Pickering, L. Georgiy, G.L. Stenchikov, D.J. Allen, A.J. DeCaria, B. Ridley, R.F. Lin, S. Lang, W.-K. Tao, 2010. Production of lightning NOx and its vertical distribution calculated from three-dimensional cloud-scale chemical transport model simulations, J. Geophys. Res., 115, D04301.

Ott, L.E., K.E. Pickering, G. Stenchikov, H. Huntrieser, and U. Schumann, 2007. Effects of lightning $\mathrm{NO}_{\mathrm{X}}$ production during the 21 July European Lightning Nitrogen Oxides Project storm studied with a three-dimensional cloud-scale chemical transport model, $J$. Geophys. Res., 112, D05307.

Pickering, K.E., Y. Wang, W.-K. Tao, C. Price, J.-F. Mueller, 1998. Vertical distributions of lightning $\mathrm{NO}_{\mathrm{x}}$ for use in regional and global transport models, J. Geophys. Res., 103, $31203-31216$.

Price, C., J. Penner, M. Prather, 1997. $\mathrm{NO}_{\mathrm{x}}$ from lightning, 1, Global distribution based on lightning physics, J. Geophys. Res., 102, 5929-5941.

Proctor, D.E., 1991. Regions where lightning flashes began, J. Geophys. Res., 96 (D3), 50995112.

Pruppacher, H.R. and J.D. Klett, 1997. Microphysics of Clouds and Precipitation, $2^{\text {nd }}$ ed., Kluwer Academic Press, 348 pp.

Rakov, V.A., and M.A. Uman, 2003. Lightning Physics and Effects, Cambridge University Press, pp. 687.

Ray, P.S., D.R. MacGorman, W.D. Rust, W.L. Taylor, L.W. Rasmussen, 1987. Lightning location relative to storm structure in a supercell storm and a multicell storm, J. Geophys. Res., 92, 5713-5724. 
Ridley, B.A., K.E. Pickering, J.E. Dye, 2005. Comments on the parameterization of lightningproduced NO in global chemistry-transport models, Atmos. Environ., 39, 6184-6187.

Rinehart, R.E., 2010. Radar for Meteorologists, $5^{\text {th }}$ Ed, Rinehart Publications, pp. 482, ISBN 978-0-9658002-3-5.

Rison, W., R. J. Thomas, P. R. Krehbiel, T. Hamlin, J. Harlin, 1999. A GPS-based threedimensional lightning mapping system: Initial observations in central New Mexico, Geophys. Res. Lett., 26, 3573-3576, doi:10.1029/1999GL010856.

Rust, W. D., and Coauthors, 2005. Inverted-polarity electrical structures in thunderstorms in the Severe Thunderstorm Electrification and Precipitation Study (STEPS), Atmos. Res., 76, 247-271, doi:10.1016/j.atmosres.2004.11.029.

Saunders, C.P.R., 1993. A review of thunderstorm electrification processes, J. Appl. Meteor., 32, $642-655$.

Saunders, C.P.R., Keith, W.D., and Mitzeva, R.P., 1991. The effect of liquid water on thunderstorm charging, J. Geophys. Res, 96, 11007 - 11017.

Schultz, C.J., W.A. Petersen, L.D. Carey, 2009. Preliminary Development and Evaluation of Lightning Jump Algorithms for the Real-Time Detection of Severe Weather, J. Appl. Meteor. Climatol., 48, 2543-2563.

Schumann, U. and H. Huntrieser, 2007. The global lightning-induced nitrogen oxides source, Atmos. Chem. Phys., 7, $3828-3907$.

Schuur, T.J. and S.A. Rutledge, 2000. Electrification of stratiform regions in mesoscale convective systems. Part I: An observational comparison of symmetric and asymmetric MCSs, J. Atmos. Sci., 57 (13), 1961 - 1982. 
Schuur, T.J., B.F. Smull, W.D. Rust, T.C. Marshall, 1991. Electrical and kinematic structure of the stratiform precipitation region trailing an Oklahoma squall line, J. Atmos. Sci., 48, $825-841$.

Singh, H.B, and co-authors, 1996. Reactive nitrogen and ozone over the western Pacific: Distribution, partitioning, and sources, J. Geophys. Res., 101, $1793-1808$.

Steiger, S.M., R.E. Orville, L.D. Carey, 2007. Total lightning signatures of thunderstorm intensity over North Texaz. Part I: Supercells, Mon. Wea. Rev., 135, 3281-3302.

Stolzenburg, M., T.C. Marshall, W.D. Rust, B.F. Smull, 1994. Horizontal distribution of electrical and meteorological conditions across the stratiform region of a mesoscale convective region, Mon. Wea. Rev., 122, 1777-1797.

Stolzenburg, M., W.D. Rust, B.F. Smull, T.C. Marshall, 1998a. Electrical structure in thunderstorm convective regions 1. Mesoscale convective systems, J. Geophys. Res. 103, 14059-14078.

Stolzenburg, M., W.D. Rust, T.C. Marshall, 1998b. Electrical structure in thunderstorm convective regions 2. Isolated storms, J. Geophys. Res. 103, 14079-14096.

Stolzenburg, M., W.D. Rust, T.C. Marshall, 1998c. Electrical structure in thunderstorm convective regions 3. Synthesis, J. Geophys. Res. 103, 14097-14108.

Takahashi, T., 1978. Riming electrification as a charge generation mechanism in thunderstorms, J. Atmos. Sci., 35, $1536-1548$.

Thomas, R.J., P.R. Krehbiel, W. Rison, T. Hamlin, J. Harlin, D. Shown, 2001. Observations of VHF source powers radiated by lightning, Geophys. Res. Lett., 28(1), 143-146, doi:10.1029/2000GL011464. 
Thomas, R., P. Krehbiel, W. Rison, J. Harlin, T. Hamlin and N. Campbell, 2003. The LMA flash algorithm, Proc. 12th Int. Conf. On Atmospheric Electricity, Versailles, France, International Commission on Atmospheric Electricity, 655 - 656.

Vuković, Z.R., Ćurić, M., 1998. The acoustic-electric coalescence and the intensification of precipitation radar echoes in clouds, Atmos. Res., 47-48, 113-125. doi:10.1016/S01698095(98)00054-4.

Vuković, Z.R., Ćurić, M., 2005. The influence of the acoustic-electric coalescence on phase and mass transfer of supercooled drops, Pure Appl. Geophys. 162, 2453-2477. doi:10.1007/s00024-005-2781-9.

Wang, T., A.W. DeSilva, G.C. Goldenbaum, R.R. Dickerson, 1998. Nitric oxide production by simulated lightning: Dependence on current, energy, and pressure, J. Geophys. Res. 103, 19149-19159.

Weiss, S.A., D.R. MacGorman, K.M. Calhoun, 2012. Lightning in the anvils of supercell thunderstorms, Mon. Wea. Rev., 140, 2064-2079.

Weisman, M.L. and J.B.Klemp, 1986. Characteristics of Isolated Convective Storms, In Mesoscale Meteorology and Forecasting, P.S. Ray, Ed., Amer. Meter. Soc., 331 - 358.

Wiens, K. C., S.A. Rutledge, and S.A. Tessendorf, 2005. The 29 June 2000 Supercell observed during STEPS. Part II: Lightning and Charge Structure. J. Atmos. Sci., 62, 4151-4177.

Wilks, D.S., 2011. Statistical Methods in the Atmospheric Sciences, $3^{\text {rd }}$ edition, Elsevier Publishers, 676 pp.

Zang, R., X. Tie, D.W. Bond, 2003. Impacts of anthropogenic and natural NOx sources over the U.S. on tropospheric chemistry, Proc. Natl. Acad. Sci., USA, 100, $1505-1509$. 
Zel'dovich Y.B. and Y.P. Raizer, 1966. Physics of Shock Waves and High-Temperature Hydrodynamic Phenomena, Academic Press, New York, pp. 464.

Zhang, J., K. Howard, J.J. Gourley, 2005. Constructing three-dimensional multiple radar reflectivity mosaics: Examples of convective storms and stratiform rain echoes, J. Atmos. Oceanic Technol., 22, 30-42.

Zhang, J., K. Howard, C. Langston, S. Vasiloff, B. Kaney, A. Arthur, S. Van Cooten, K. Kelleher, D. Kitzmiller, F. Ding, D.-J. Seo, E. Wells, C. Dempsey, 2011. National Mosaic and multi-sensor QPE (NMQ) system: Description, results and future plans, Bull. Amer. Met. Soc., 92, 1321-1338.

Zhang, J., S. Wang, B. Clarke, 2004. WSR-88D reflectivity quality control using horizontal and vertical reflectivity structure, Preprints, $11^{\text {th }}$ Conf. on Aviation, Range, and Aerospace Meteorology, Hyannis, MA., Amer. Meteor. Soc., 5.4. (Available online at http://ams.confex.com/ams/pdfpapers/81858.pdf) 


\section{Tables}

TABLE 1: Indicating how the flash types were grouped for the specific flash typing analysis.

\begin{tabular}{|l|l|}
\hline Flash Type & \multicolumn{1}{|c|}{ Classified Flash } \\
\hline \multirow{2}{*}{ CG } & Normal Negative CG \\
\cline { 2 - 2 } & Normal Positive CG \\
\hline \multirow{4}{*}{ IC } & Normal IC \\
\cline { 2 - 2 } & Inverted IC \\
\hline \multirow{3}{*}{ Hybrid } & Normal IC-CG Hybrid Negative CG \\
\cline { 2 - 2 } & Normal IC-CG Hybrid Positive CG \\
\hline
\end{tabular}


TABLE 2: Summary of convective parameters for the multicell, MCS and supercell case days. For the multicell, the UAH mobile RAOB that was taken near Capshaw, Alabama at 2037 UTC was used. The 1200 UTC BMX sounding data was used for the MCS case, while the 0000 UTC BMX on 20140429 was used for the supercell case, as this was more representative. Both of these BMX sounding profiles were obtained from the UWYO website.

\begin{tabular}{|l|c|c|c|}
\hline \multicolumn{1}{|c|}{ Convective Parameters } & $\begin{array}{c}\mathbf{2 0 1 2 0 5 2 1} \\
\mathbf{2 0 3 7} \text { UTC }\end{array}$ & $\begin{array}{c}\mathbf{2 0 1 4 0 4 0 4} \\
\mathbf{1 2 0 0} \text { UTC }\end{array}$ & $\begin{array}{c}\mathbf{2 0 1 4 0 4 2 9} \\
\mathbf{0 0 0 0} \text { UTC }\end{array}$ \\
\hline $\begin{array}{l}\text { 0 - 6 km shear (deep layer wind } \\
\text { magnitude difference) }\end{array}$ & $\begin{array}{c}2.0 \times 10^{-4} \mathrm{~s}^{-1} \\
\left(1.2 \mathrm{~m} \mathrm{~s}^{-1}\right)\end{array}$ & $\begin{array}{c}3.2 \times 10^{-4} \mathrm{~s}^{-1} \\
\left(19.55 \mathrm{~m} \mathrm{~s}^{-1}\right)\end{array}$ & $\begin{array}{c}3.9 \times 10^{-4} \mathrm{~s}^{-1} \\
\left(23.7 \mathrm{~m} \mathrm{~s}^{-1}\right)\end{array}$ \\
\hline CAPE & $785 \mathrm{~J} \mathrm{~kg}^{-1}$ & $367 \mathrm{~J} \mathrm{~kg}^{-1}$ & $1,276 \mathrm{~J} \mathrm{~kg}^{-1}$ \\
\hline $0^{\circ} \mathrm{C}$ level & $3.5 \mathrm{~km}$ & $3.6 \mathrm{~km}$ & $4.2 \mathrm{~km}$ \\
\hline$-10^{\circ} \mathrm{C}$ level & $5.5 \mathrm{~km}$ & $5.3 \mathrm{~km}$ & $5.5 \mathrm{~km}$ \\
\hline$-40^{\circ} \mathrm{C}$ level & $9.5 \mathrm{~km}$ & $9.3 \mathrm{~km}$ & $9.8 \mathrm{~km}$ \\
\hline
\end{tabular}


TABLE 3: Altitudes and temperatures of the location of largest frequency of flash initiation and propagation per storm type.

\begin{tabular}{|l|l|c|c|c|c|}
\hline \multicolumn{2}{|c|}{} & $\begin{array}{c}\text { Initiation } \\
\text { Altitude }(\mathbf{k m})\end{array}$ & $\begin{array}{c}\text { Initiation } \\
\text { Temperature } \\
\left({ }^{\circ} \mathbf{C}\right)\end{array}$ & $\begin{array}{c}\text { Propagation } \\
\text { Altitude }(\mathbf{k m})\end{array}$ & $\begin{array}{c}\text { Propagation } \\
\text { Temperature } \\
\left({ }^{\circ} \mathbf{C}\right)\end{array}$ \\
\hline \multirow{4}{*}{20120521} & All & 6.0 to 7.0 & -13.5 to -20.5 & 8.0 to 9.0 & -28.3 to -36.2 \\
\cline { 2 - 6 } & IC & 6.0 to 7.0 & -13.5 to -20.5 & 8.0 to 9.0 & -28.3 to -36.2 \\
\cline { 2 - 6 } & CG & 2.0 to 3.0 & 10.8 to 3.8 & 3.0 to 4.0 & 3.8 to -2.0 \\
\cline { 2 - 6 } & Hybrid & 7.0 to 9.0 & -20.5 to -36.2 & 9.0 to 10.0 & -36.2 to -44.8 \\
\hline \multirow{3}{*}{20140404} & All & 4.0 to 5.0 & -2.9 to -8.7 & 7.0 to 8.0 & -22.5 to -31.1 \\
\cline { 2 - 6 } & IC & 6.0 to 7.0 & -15.3 to -22.5 & 7.0 to 8.0 & -22.5 to -31.1 \\
\cline { 2 - 6 } & CG & 4.0 to 5.0 & -2.9 to -8.7 & 4.0 to 5.0 & -2.9 to -8.7 \\
\cline { 2 - 6 } & Hybrid & 6.0 to 7.0 & -15.3 to -22.5 & 8.0 to 9.0 & -31.1 to -38.2 \\
\hline & All & 10.0 to 11.0 & -42.5 to -50.6 & 10.0 to 11.0 & -42.5 to -50.6 \\
\cline { 2 - 6 } & IC & 10.0 to 11.0 & -42.5 to -50.6 & 10.0 to 11.0 & -42.5 to -50.6 \\
\cline { 2 - 6 } & CG & 4.0 to 5.0 & -0.5 to -8.0 & 4.0 to 5.0 & -0.5 to -8.0 \\
\cline { 2 - 6 } & Hybrid & 10.0 to 11.0 & -42.5 to -50.6 & 10.0 to 11.0 & -42.5 to -50.6 \\
\hline
\end{tabular}


TABLE 4: Percentage of VHF source locations where $\mathrm{Z}<20 \mathrm{dBZ}$ and $\mathrm{Z} \geq 40 \mathrm{dBZ}$ for flash initiation and propagation per storm type.

\begin{tabular}{|c|c|c|c|c|c|}
\hline & & \multicolumn{2}{|c|}{ Initiation } & \multicolumn{2}{|c|}{ Propagation } \\
\hline & & $\% \mathrm{Z}<20 \mathrm{dBZ}$ & $\% \mathrm{Z} \geq 40 \mathrm{dBZ}$ & $\% \mathrm{Z}<20 \mathrm{dBZ}$ & $\% \mathrm{Z} \geq 40 \mathrm{dBZ}$ \\
\hline \multirow{4}{*}{20120521} & All & 29.7 & 10.9 & 47.1 & 5.6 \\
\hline & IC & 40.9 & 4.5 & 54.4 & 2.7 \\
\hline & CG & 20.0 & 33.3 & 13.8 & 18.4 \\
\hline & Hybrid & 14.3 & 0.0 & 43.2 & 6.6 \\
\hline \multirow{4}{*}{20140404} & All & 15.9 & 5.4 & 31.0 & 2.0 \\
\hline & IC & 23.8 & 3.7 & 37.5 & 0.8 \\
\hline & CG & 11.8 & 7.4 & 13.1 & 8.9 \\
\hline & Hybrid & 19.3 & 4.5 & 38.0 & 0.7 \\
\hline \multirow{4}{*}{20140428} & All & 6.9 & 11.0 & 11.7 & 33.1 \\
\hline & IC & 6.9 & 44.3 & 12.1 & 30.3 \\
\hline & CG & 4.8 & 62.0 & 4.3 & 48.9 \\
\hline & Hybrid & 6.6 & 49.2 & 16.7 & 24.5 \\
\hline
\end{tabular}


TABLE 5: Comparison showing the percentage of occurrence of each flash type relative to all flashes as well as how the mean size of each flash type compares to the mean and summed size of all flashes.

\begin{tabular}{|c|c|c|c|c|c|}
\hline & $\begin{array}{c}\text { Number } \\
\text { of Flashes }\end{array}$ & $\begin{array}{c}\text { Mean } \\
\text { Flash Size } \\
(\mathbf{k m})\end{array}$ & $\begin{array}{c}\text { Total } \\
\text { Length } \\
(\mathbf{k m})\end{array}$ & $\begin{array}{l}\text { Percentage } \\
\text { of All } \\
\text { Flashes (\%) }\end{array}$ & $\begin{array}{l}\text { Percentage } \\
\text { Length to } \\
\text { Total Flash } \\
\text { Length (\%) }\end{array}$ \\
\hline \multicolumn{6}{|c|}{20120521 Multicell } \\
\hline All Flashes & 104 & 8.11 & 843.10 & 100.00 & $100.00 *$ \\
\hline IC Flashes & 44 & 8.41 & 369.93 & 42.31 & 43.88 \\
\hline CG Flashes & 15 & 5.59 & 83.89 & 14.42 & 9.95 \\
\hline Hybrid Flashes & 7 & 12.65 & 88.55 & 6.73 & 10.50 \\
\hline \multicolumn{6}{|c|}{20140404 MCS } \\
\hline All Flashes & 2,342 & 11.02 & $25,811.81$ & 100.00 & $100.00 *$ \\
\hline IC Flashes & 441 & 12.40 & $5,466.92$ & 18.83 & 21.18 \\
\hline CG Flashes & 328 & 9.07 & $2,973.49$ & 14.01 & 11.52 \\
\hline Hybrid Flashes & 380 & 17.80 & $6,763.69$ & 16.23 & 26.20 \\
\hline \multicolumn{6}{|c|}{20140428 Supercell } \\
\hline All Flashes & 72,068 & 5.73 & $412,784.43$ & 100.00 & $100.00^{*}$ \\
\hline IC Flashes & 36,763 & 5.58 & $205,013.26$ & 51.01 & 49.67 \\
\hline CG Flashes & 1,847 & 8.53 & $15,759.47$ & 2.56 & 3.82 \\
\hline Hybrid Flashes & 5,825 & 9.53 & $55,485.15$ & 8.08 & 13.44 \\
\hline
\end{tabular}

* The total number of ambiguously classified flashes were 38 (36.5\%), 1,193 (50.9\%) and $27,633(38.3 \%)$ for the multicell, MCS and supercell storms, respectively. 
Figures
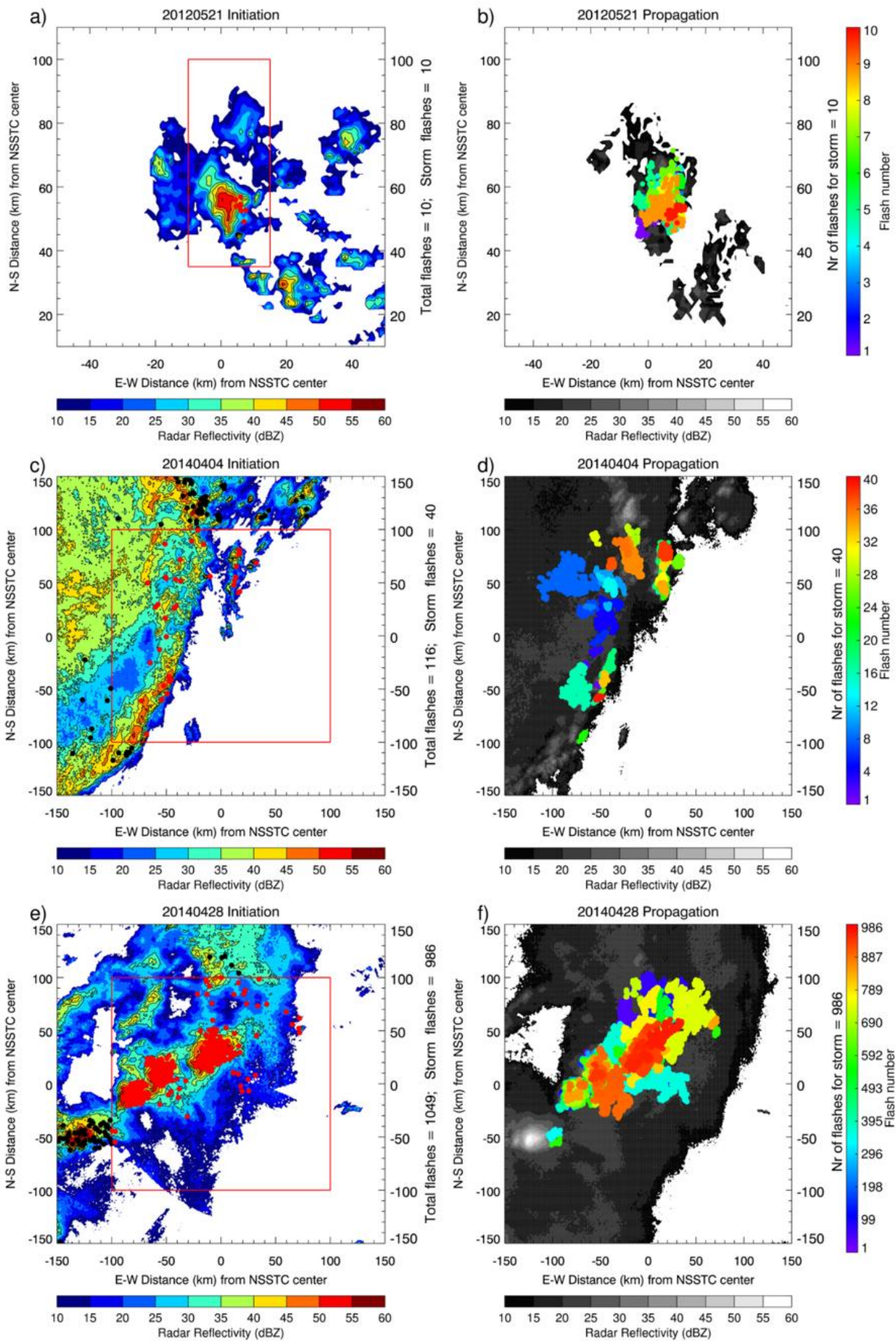

FIGURE 1: Summary depiction of the evolution of the MRMS radar and NALMA lightning structure in $(a, b)$ the multicell storm cluster; (c, d) the MCS and (d, e) the supercells. Left (a, c, e) shows $\mathrm{Z}(\mathrm{dBZ})$ at $2 \mathrm{~km}$ altitude in color shade and flash initiation points that occurred within $100 \mathrm{~km}$ from NSSTC in red circles while flashes that initiated outside this range are shown in black circles. The red box depicts the radar and lightning analysis domain. Right (b, d, f) shows 
$\mathrm{Z}$ (in dBZ) at $8 \mathrm{~km}$ altitude in gray shade and all NALMA VHF sources associated with the individual flashes (color coded by flash). Note that the $\mathrm{Z}$ scale for all panels is from 10-60 dBZ. 

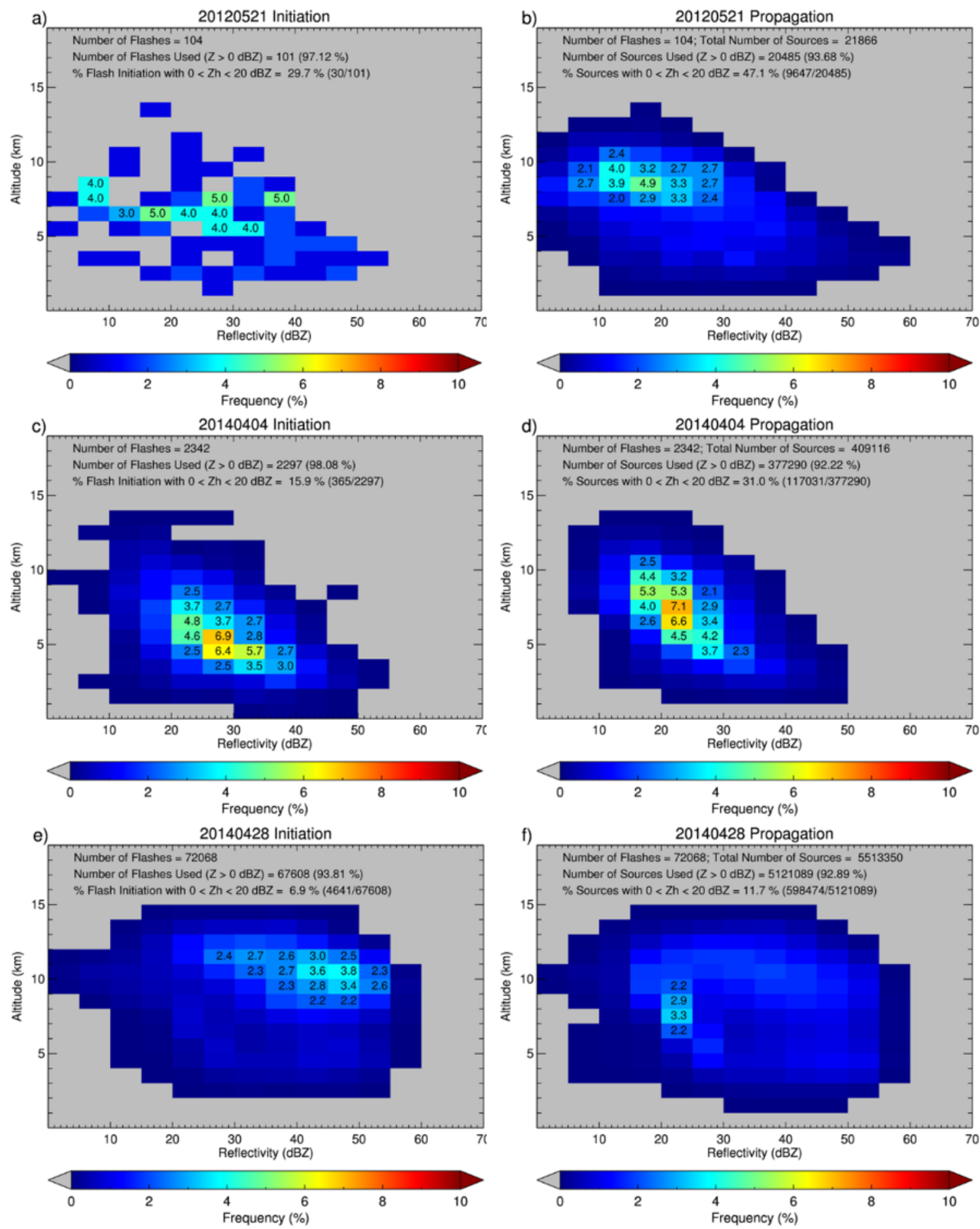

FIGURE 2: 2D histogram of flash initiation (left) and flash propagation (right) altitude compared to radar $\mathrm{Z}$ for $(\mathrm{a}, \mathrm{b})$ the multicell storm, $(\mathrm{c}, \mathrm{d})$ the MCS, and $(\mathrm{e}, \mathrm{f})$ the embedded supercells. 
a)

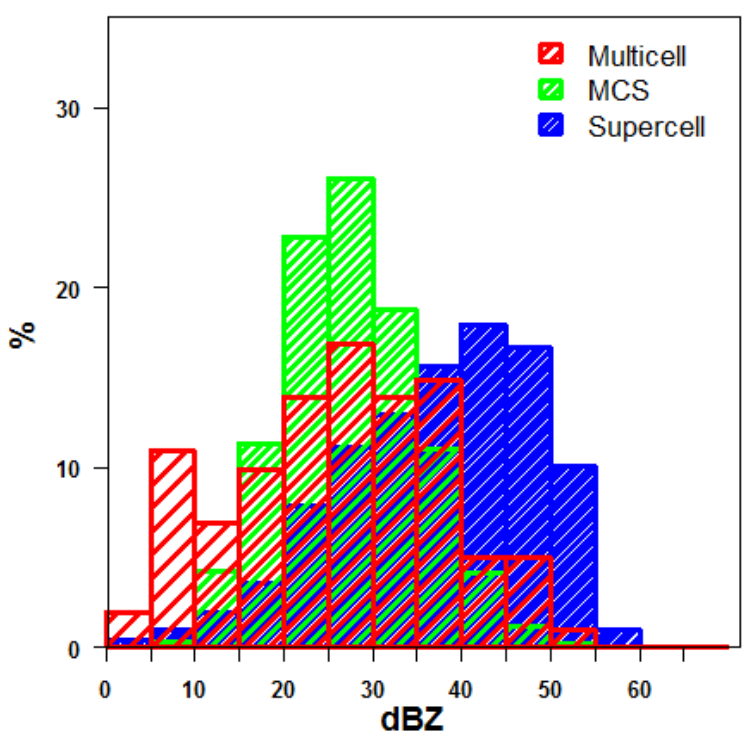

c)

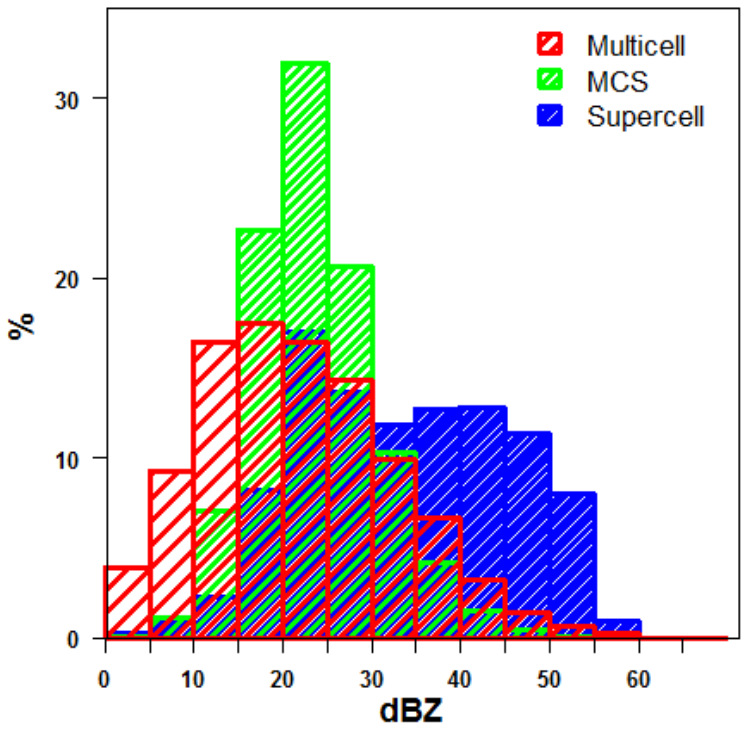

b)

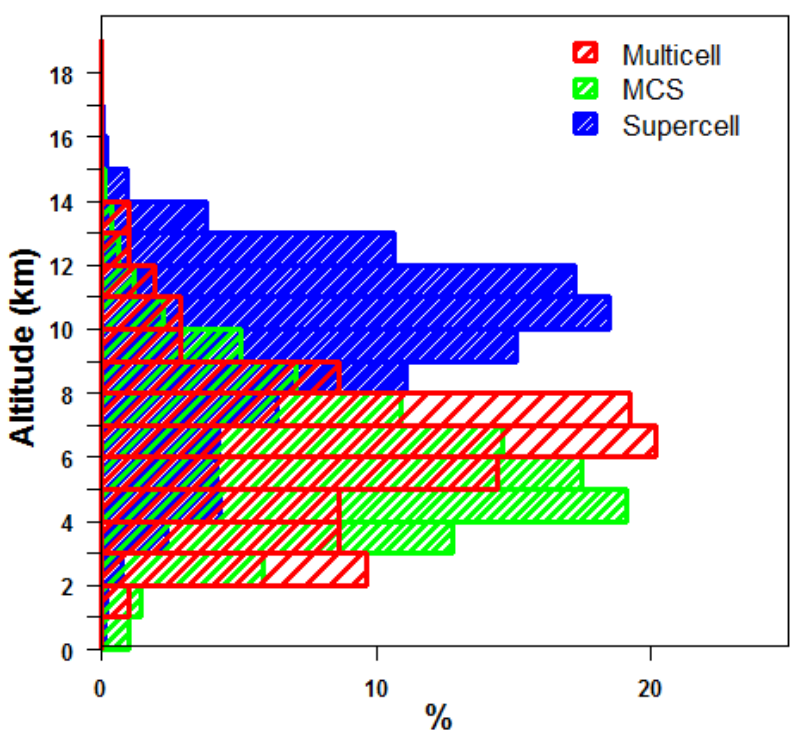

d)

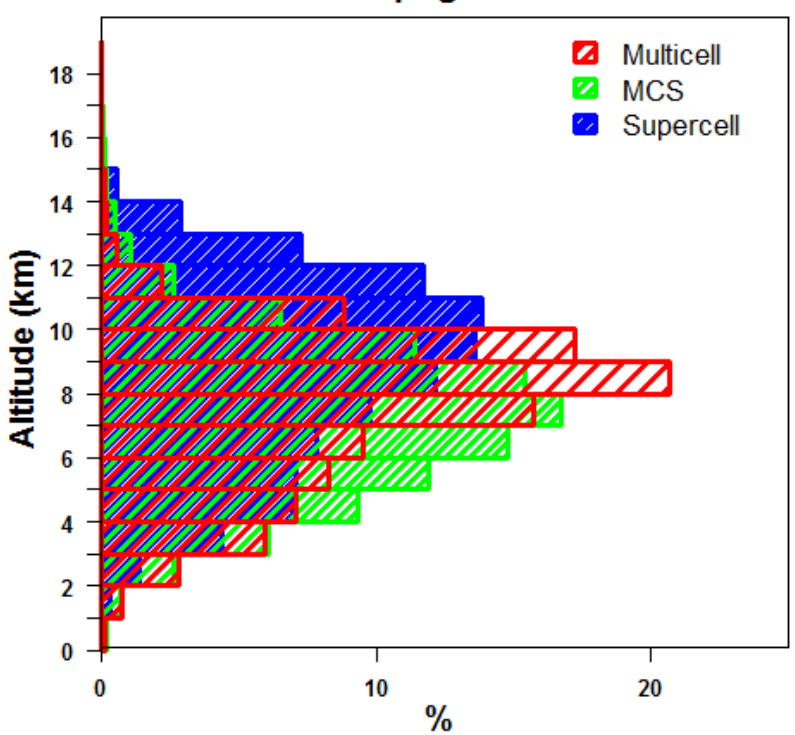

FIGURE 3: Similar to Fig. 2, but showing the 1D histogram relative to Z only (a and c) and 1D histogram for flash initiation points relative to altitude only (b and d) for the multicell (red), MCS (green) and supercell (blue) storms. The top row shows the results for the flash initiation points only and the bottom row shows the results for the flash propagation (i.e., all NALMA VHF sources related to the flashes). 
a)

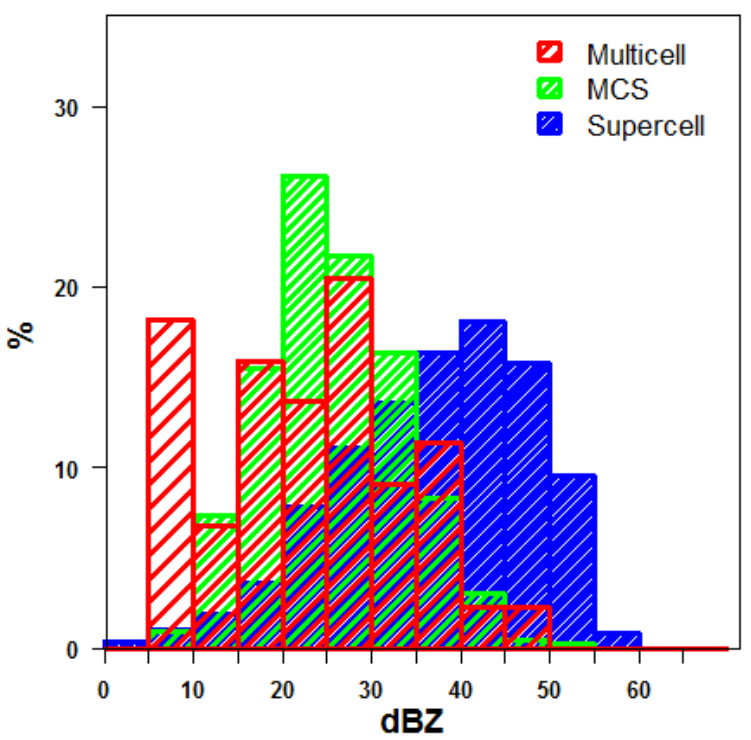

c)

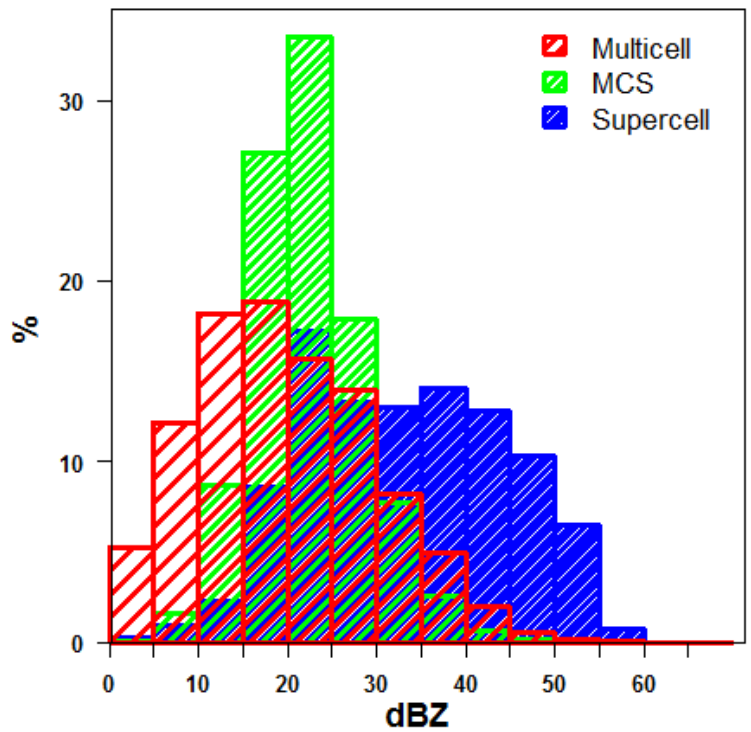

b)

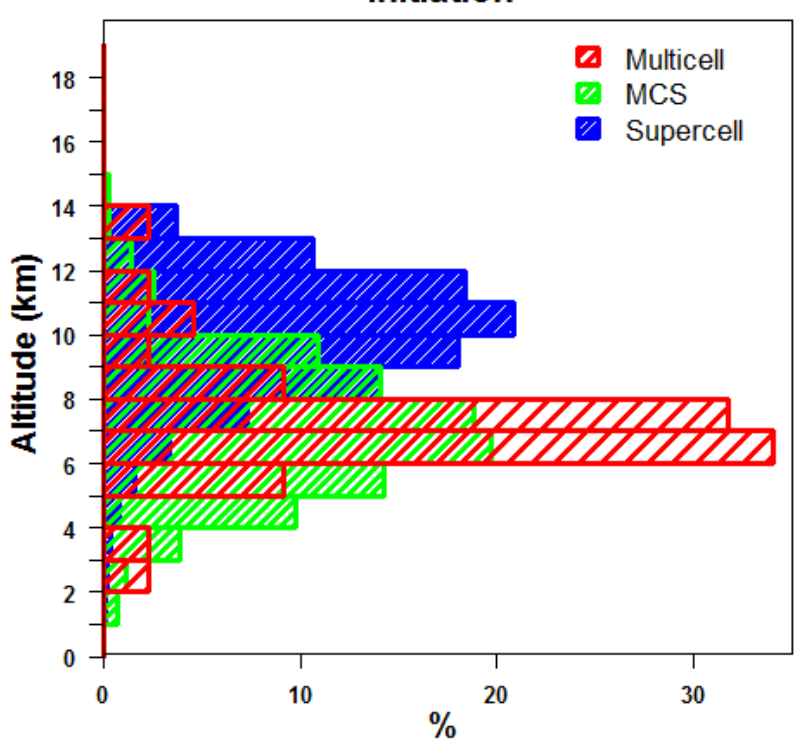

d)

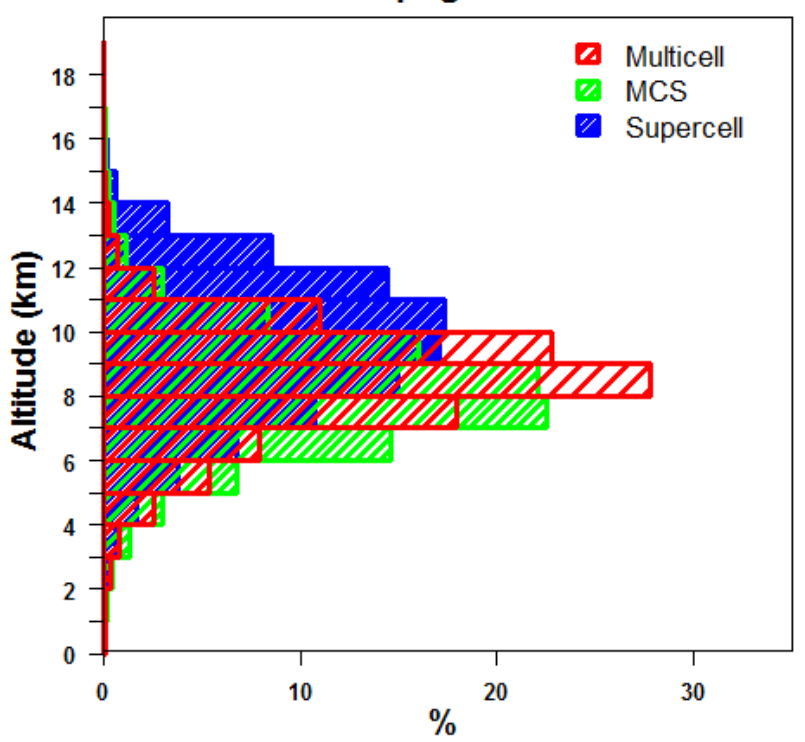

FIGURE 4: Same as Fig. 3, but for IC flashes only. 
a)

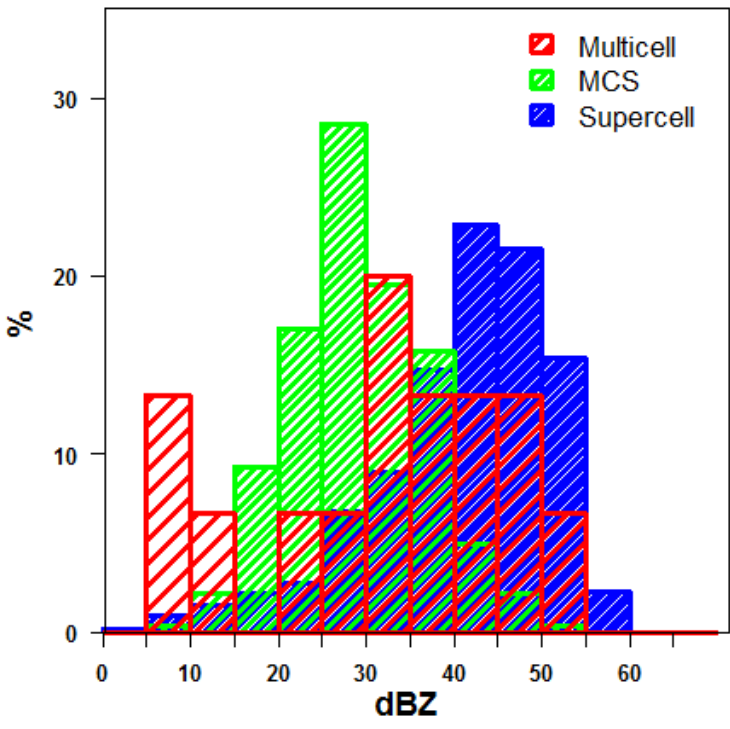

c)

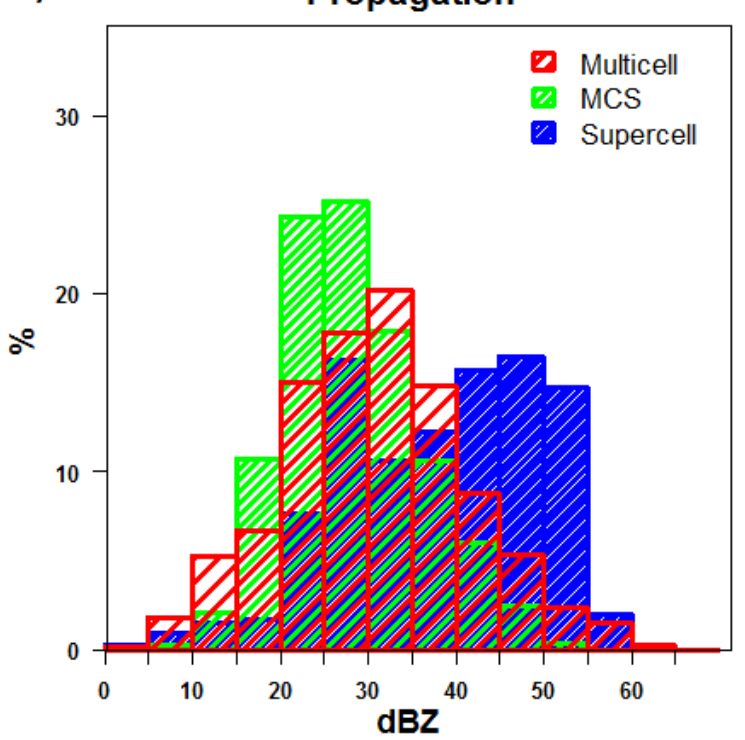

b) Initiation

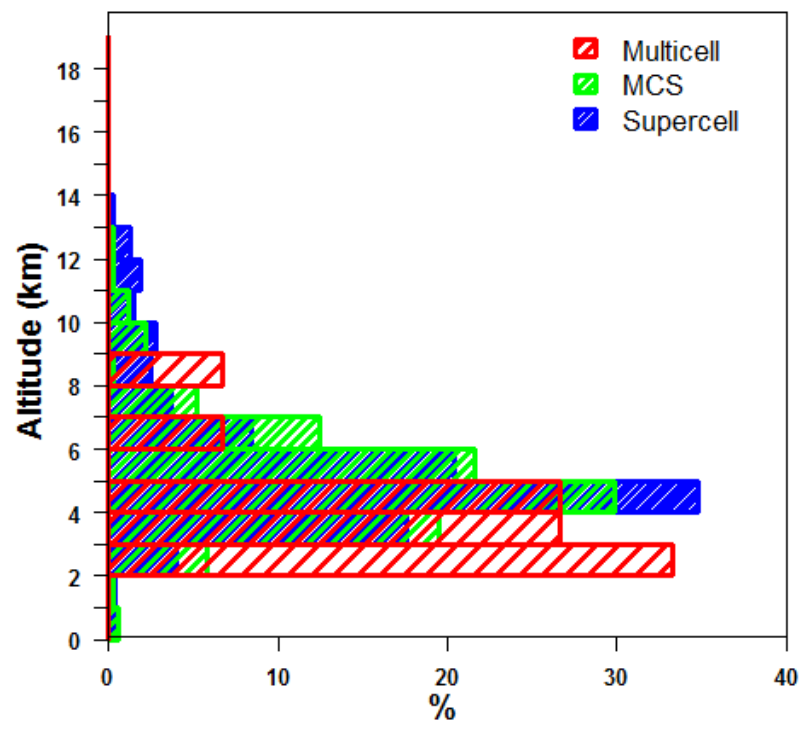

d)

Propagation

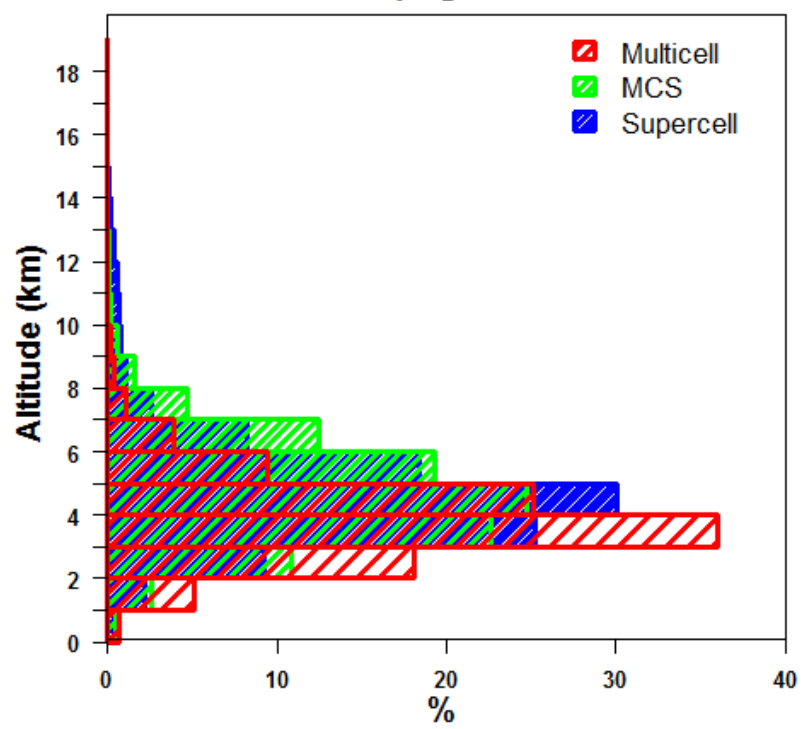

FIGURE 5: Same as Fig. 4, but for CG flashes only. 
a)

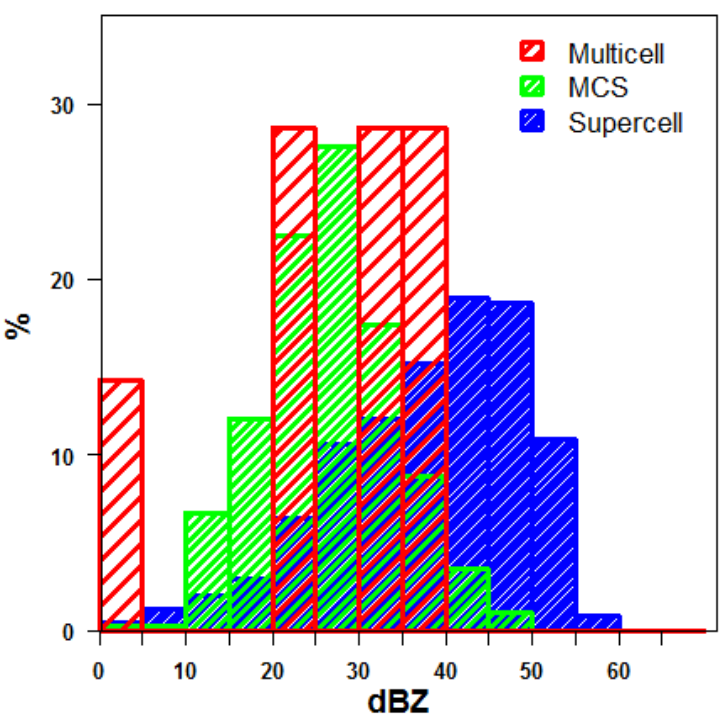

c)

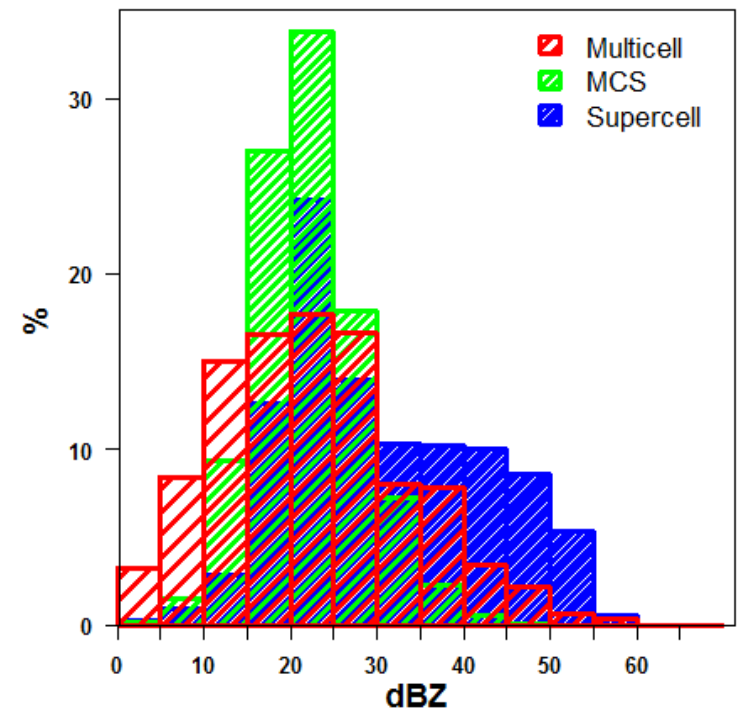

b) Initiation

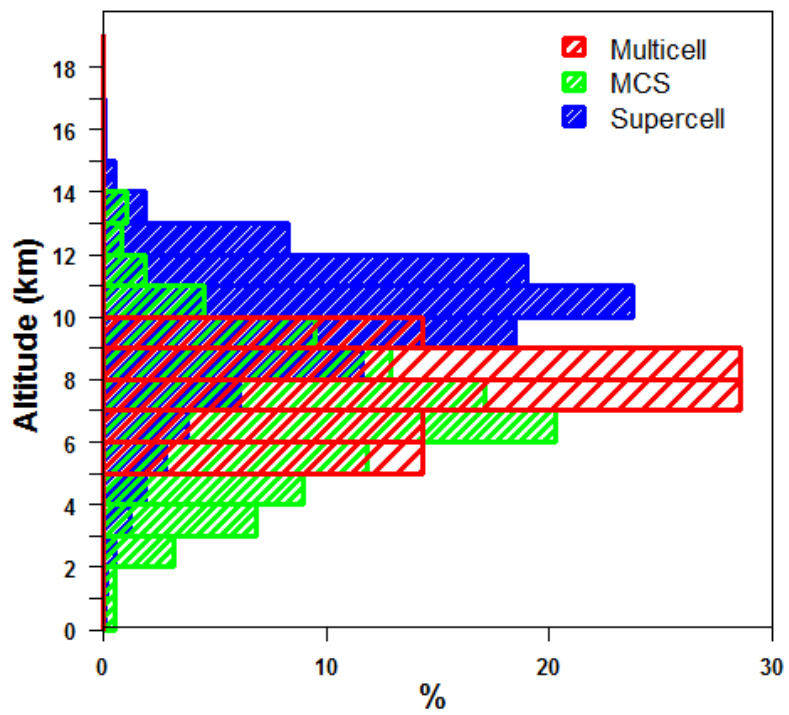

d) Propagation

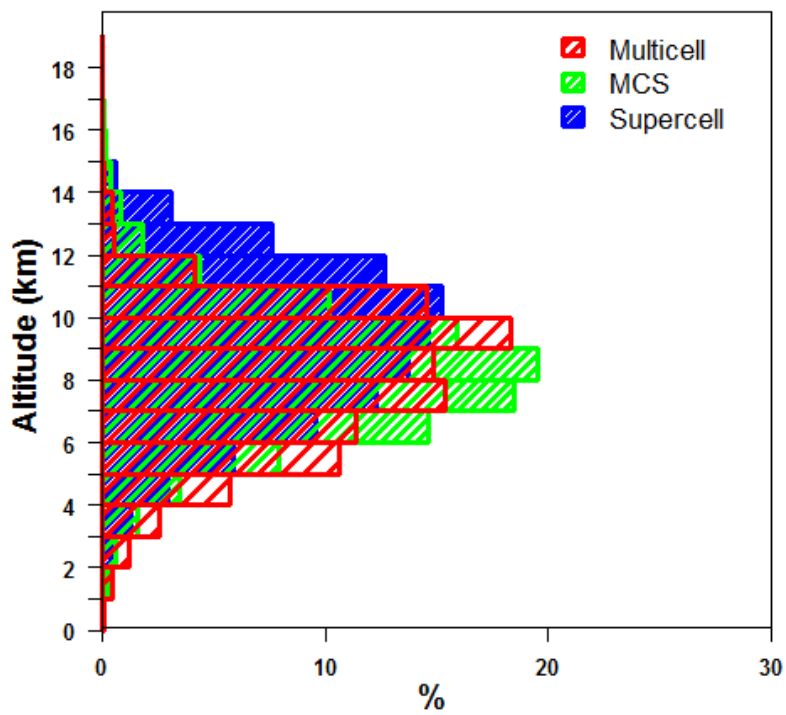

FIGURE 6: Same as Fig. 5, but for Hybrid flashes only 